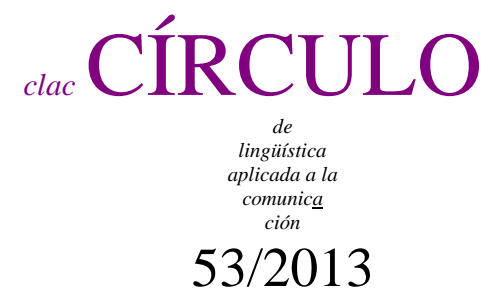

\title{
LA ENSEÑANZA DE LAS LENGUAS PROFESIONALES Y ACADÉMICAS
}

\author{
Ana Isabel Rodríguez-Piñero Alcalá \\ Universidad de Cádiz \\ isabel rodriguez en uca es
}

Resumen

La sociedad del conocimiento, la globalización, los fenómenos migratorios, las tecnologías de la información y la comunicación (TICs) constituyen todos ellos factores determinantes del interés que despierta hoy día la comunicación especializada, tanto en lo concerniente a su descripción como en lo que respecta a su adquisición y enseñanza. Asimismo, los cambios profundos que se están produciendo en la enseñanza universitaria en el marco del Espacio Europeo de Educación Superior demandan nuevas formas de abordar el proceso de enseñanza-aprendizaje. El objetivo principal de este artículo es el de ofrecer un panorama actual de las principales metodologías docentes y técnicas didácticas a la hora de diseñar un curso de lenguas con fines profesionales y académicos.

Palabras clave: lenguas para fines específicos, lenguas profesionales y académicas, enfoque centrado en el alumno, enfoque centrado en el proceso.

Rodríguez-Piñero Alcalá, Ana Isabel. 2013.

La enseñanza de las lenguas profesionales y académicas.

Círculo de Lingüística Aplicada a la Comunicación 53, 54-94.

http://www.ucm.es/info/circulo/no53/rpinero.pdf

DOI http://dx.doi.org/10.5209/rev_CLAC.2013.v53.41650

(C) 2013 Ana Isabel Rodríguez-Piñero Alcalá

Círculo de Lingüística Aplicada a la Comunicación (clac)

Universidad Complutense de Madrid. ISSN 1576-4737. http://www.ucm.es/info/circulo 


\begin{abstract}
Teaching professional and academic languages. The knowledge society, globalization, migration phenomena, information and communication technologies (ICTs) are all relevant factors both in relation to the description of specialised languages and to their acquisition and teaching. New approaches in teaching-learning processes are demanded by the framework of the European Space of Higher Education, due to the profound changes taking place in university education. The main goal of this article is to provide an overview of the main current teaching methods and techniques when designing a language course for professional and academic purposes.
\end{abstract}

Key words: languages for specific purposes, professional and academic languages, learner-centred approach, learning-centred approach.

Índice

1. Introducción 56

2. La comunicación especializada, las lenguas de especialidad y las lenguas con fines específicos 57

3. Las lenguas profesionales y académicas 62

3.1. Lenguas para fines profesionales (LFP) 65

3.2. Lenguas para fines académicos (LFA) 67

4. La organización del proceso de enseñanza-aprendizaje de las LFE 70

5. Métodos y técnicas de trabajo 75

5.1. La simulación global 77

5.2. El enfoque por tareas 78

5.3. El aprendizaje orientado a proyectos 79

5.4. Presentaciones orales 80

5.5. El método de casos 81

5.6. El aprendizaje cooperativo 83

5.7. El aprendizaje basado en problemas 85

6. Conclusiones 87

Referencias bibliográficas 87 


\section{Introducción}

La sociedad del conocimiento, la globalización, los fenómenos migratorios, las tecnologías de la información y la comunicación (TICs) constituyen todos ellos factores determinantes en la relevancia que la especialidad ha adquirido en los últimos tiempos ${ }^{1}$. Asimismo, los cambios profundos que se están produciendo en la enseñanza universitaria en el marco del Espacio Europeo de Educación Superior demandan nuevas formas de abordar el proceso de enseñanza-aprendizaje. El objetivo principal de este artículo es el de ofrecer un panorama actual de las principales metodologías docentes y técnicas didácticas a la hora de diseñar un curso de lenguas con fines profesionales y académicos. La organización de este trabajo se articula en cuatro apartados, además de esta introducción, conclusiones y referencias bibliográficas utilizadas. En el primero de ellos, se introduce una delimitación conceptual y terminológica entre comunicación especializada, lenguas de especialidad y lenguas con fines específicos. A continuación, se circunscriben los propósitos específicos al contexto profesional y académico, restringiendo de ese modo los ámbitos de acción de este campo de estudio, y se presentan los rasgos más destacados de las lenguas profesionales y académicas. En los dos últimos puntos de este trabajo, se profundiza en la organización del proceso de enseñanza-aprendizaje de los lenguajes especializados con fines académicos y profesionales y en las técnicas didácticas que con mayor frecuencia se emplean para su pedagogía, desde un enfoque centrado en el alumno y orientado hacia los procesos y el aprendizaje significativo.

\footnotetext{
${ }^{1}$ Este trabajo se inserta en las líneas de investigación "Metodología en la enseñanza-aprendizaje de lenguas extranjeras" y "Terminología y lenguajes especializados", que estamos desarrollando en el marco del grupo de investigación de excelencia de la Junta de Andalucía "Semaínein" (HUM 147) y parcialmente en el proyecto motriz "Comunicación integral y planificación lingüística como estrategia para el desarrollo del sector de la piel en Andalucía” (Ref. HUM6823), concedido al mencionado grupo y a la empresa Fundación Centro Tecnológico de la Piel de Andalucía (MOVEX) y financiado en su convocatoria de 2010 por la Dirección General de Universidades, Investigación y Tecnología de la Consejería de Innovación, Ciencia y Empresa de la Junta de Andalucía.
} 
2. La comunicación especializada, las lenguas de especialidad y las lenguas con fines específicos

En las últimas décadas, se ha producido un paulatino aumento de interés por la comunicación especializada, tanto en lo concerniente a su descripción y caracterización como en lo que respecta a su adquisición y enseñanza. Prueba de ello, son los numerosos encuentros científicos que se celebran en torno a esta temática, como las diversas ediciones de los congresos de AELFE (Asociación Europea de Lenguas para Fines Específicos), los Coloquios Internacionales de Historia de los Lenguajes Iberorrománicos de Especialidad, los Encuentros Internacionales de GERES (Groupe d’Étude et de Recherche en Espagnol de Spécialité), los Encuentros sobre el Español como Lengua de Especialidad que anualmente organiza la Fundación Comillas en colaboración con la Universidad de Alcalá y la Universidad de Cantabria, las Jornadas que la Universidad de Alcalá dedica a las Lenguas para Fines Específicos. Investigación y enseñanza o los Congresos Internacionales sobre la Enseñanza del Español con Fines Específicos (CIEFE). Entre los factores que se señalan como los responsables del interés que despiertan ambos aspectos de las lenguas especializadas destaca la relevancia que ha adquirido la especialidad en la sociedad actual, fomentada por una globalización, que exige una constante transferencia de productos y conocimientos y que origina necesidades en materia de multilingüismo ${ }^{2}$. Según Alcaraz Varó (2007: 3) es esta sociedad en la que vivimos, la denominada Sociedad de la Información, Sociedad del Conocimiento, o Sociedad de la Información y el Conocimiento $(\mathrm{SIC})^{3}$, la que ha impulsado el desarrollo que ha experimentado la investigación y la enseñanza de las lenguas profesionales y académicas. Este impulso se debe, por un lado, a la necesidad de analizar tanto los rasgos definitorios de estas

\footnotetext{
2 Junto con los movimientos globalizadores, Cabré y Gómez de Enterría (2006:10-11) le conceden también un papel primordial al reconocimiento que están teniendo desde diversos ámbitos los logros obtenidos en la Lingüística aplicada y al trascendental labor que desempeña esta en el marco de la Lingüística general.

${ }^{3}$ Para Alcaraz Varó (2007: 4-5), conocimiento e información, aunque frecuentemente empleados como sinónimos, remiten a conceptos distintos, puesto que para que la información se convierta en conocimiento tiene que ser procesada, sistematizada e integrada en una parcela del saber, en un área del conocimiento, de ahí que prefiera la denominación Sociedad del Conocimiento para referirse al marco en el que se insertan las lenguas de especialidad.
} 
lenguas de especialidad como las estrategias cognitivas y comunicativas que despliegan sus actores en el desempeño de su actividad profesional, y, por otro, a la interdisciplinariedad epistemológica que surge a raíz de un nuevo replanteamiento de la división tradicional del conocimiento y que Alcaraz Varó (2007: 6-7) considera como una de las bases de la investigación en este campo:

\footnotetext{
La interdisciplinariedad es, a claras luces, uno de los pilares fundamentales que sustentan los estudios de las lenguas profesionales y académicas. [...] La interdisciplinariedad actúa como fecundo punto de encuentro de saberes que propicia la reflexión teórica y la aplicada sobre las lenguas profesionales y académicas, esto es, las lenguas de las comunidades epistemológicas de los médicos, los economistas, los juristas, los científicos, los expertos en turismo, etc. en su comunicación diaria, en sus conceptos, en sus libros de textos y en sus revistas especializadas.
}

La comunicación especializada, para Díaz Rojo (2000: 69), es el proceso de transmisión de información -especializada, añadimos- entre diversos agentes o participantes en el evento comunicativo. Según Cabré (1999: 87), la comunicación especializada está temáticamente marcada, se produce en situación profesional, pertenece a un registro formal y, además, no adquiere su significado directamente del objeto de la realidad, sino de una estructura preestablecida, y se diferencia de la comunicación general en la selección de unidades, en los modos de significar, en la frecuencia de las funciones lingüísticas que seleccionan, en la organización del discurso, etc. Las lenguas de especialidad, por su parte, representan “el instrumento imprescindible para resolver la comunicación en todos los ámbitos y áreas temáticas en los que científicos, técnicos y profesionales llevan a cabo en su trabajo” (Gómez de Enterría 2009: 20). En otras palabras, los lenguajes especializados se convierten en la lengua vernácula de comunicación en los contextos profesionales y académicos, constituyen una parte fundamental de la comunicación especializada, que está determinada, además, por otros requisitos semánticos y pragmáticos. En este sentido, Cabré et alii (2007: 851) elucidan que hemos pasado de un modelo lexicalista, basado en la descripción de los términos como unidades de códigos especializados, a un modelo discursivo, que tiene en cuenta todos los factores que inciden en el proceso comunicativo: sociodiscursivos, que incluyen los papeles de emisor y receptor como especialistas productores del discurso y los destinatarios (sean especialistas o no), y los ámbitos científicos, profesionales e institucionales en los que están inmersos; textuales, que comprenden tanto los géneros y 
tipos de discursos como las convenciones retóricas y estilísticas que regulan la construcción del discurso; cognitivos, que se refieren a las ontologías y al conjunto de proposiciones adoptados como núcleo conceptual, epistemológico e, incluso, ideológico en cada disciplina; gramaticales, que hacen alusión a las construcciones sintácticas y a los elementos morfológicos, gramaticales y léxicos más habituales, y, finalmente, terminológicos, que se identifican con los diversos tipos de unidades terminológicas, descritas según su constitución morfológica, sintáctica, etc. y las clases conceptuales que representan.

Una vez introducida la demarcación entre comunicación especializa y lengua de especialidad, cabe preguntarse si la proliferación de términos (special language, specialised language, language for specific purposes [ing.]; lengua de especialidad/especializada, lenguaje de especialidad/especializado, tecnolecto, lenguajes específicos, lengua/lenguaje para/con fines/finalidades específicas, lengua/lenguajes para/con propósitos específicos [esp.]; Technolekt, Fachsprache, Berufssprache, Fachkommunikation [al.]) que se percibe en todas las investigaciones de carácter más o menos reciente y que, en principio, parecen referirse al mismo dominio conceptual, constituyen variantes de un mismo tecnicismo o designan nociones y realidades diferentes. La necesidad de una delimitación conceptual y terminológica se justifica no solo por esta abundancia de términos, sino -y esto es lo más importanteporque toda disciplina que reclame un estatus científico debe ser cuestionada y debe someter su terminología a revisión crítica (Gómez de Enterría 2006: 49). Son muchos los autores y las teorías propuestas en torno a la concepción del lenguaje especializado frente al lenguaje general o común, autores y teorías que podrían quedar resumidas en tres grandes grupos ${ }^{4}$, en función de su descripción:

a) Las lenguas de especialidad como códigos lingüísticos completos diferenciados del lenguaje general, que constan de unidades y reglas específicas (Hoffmann 1998).

\footnotetext{
${ }^{4}$ Partimos de la síntesis realizada por Cabré (1993:132-135) sobre las diversas posturas existentes acerca de la noción de las lenguas de especialidad y que esta lingüista adopta de Beaugrande (1987).
} 
b) Las lenguas de especialidad como subsistemas o subconjuntos del sistema general, que atienden a cuestiones pragmáticas y extralingüísticas, ya sean reales (Sager et alii 1980, Picht y Draskau 1985, Varantola 1986) o virtuales (Cabré 1993, 1999, 2004).

c) Las lenguas de especialidad como variación diastrática (tecnolecto) y/o diafásica (registro) (Rey 1976, Quemada 1978, Rondeau 1983), es decir, los términos no serían más que variantes léxicas (terminológicas) de una lengua determinada.

Todas estas aproximaciones conceptuales a las lenguas de especialidad quedan esquematizadas en el siguiente gráfico de Ahmad et alii (1995):

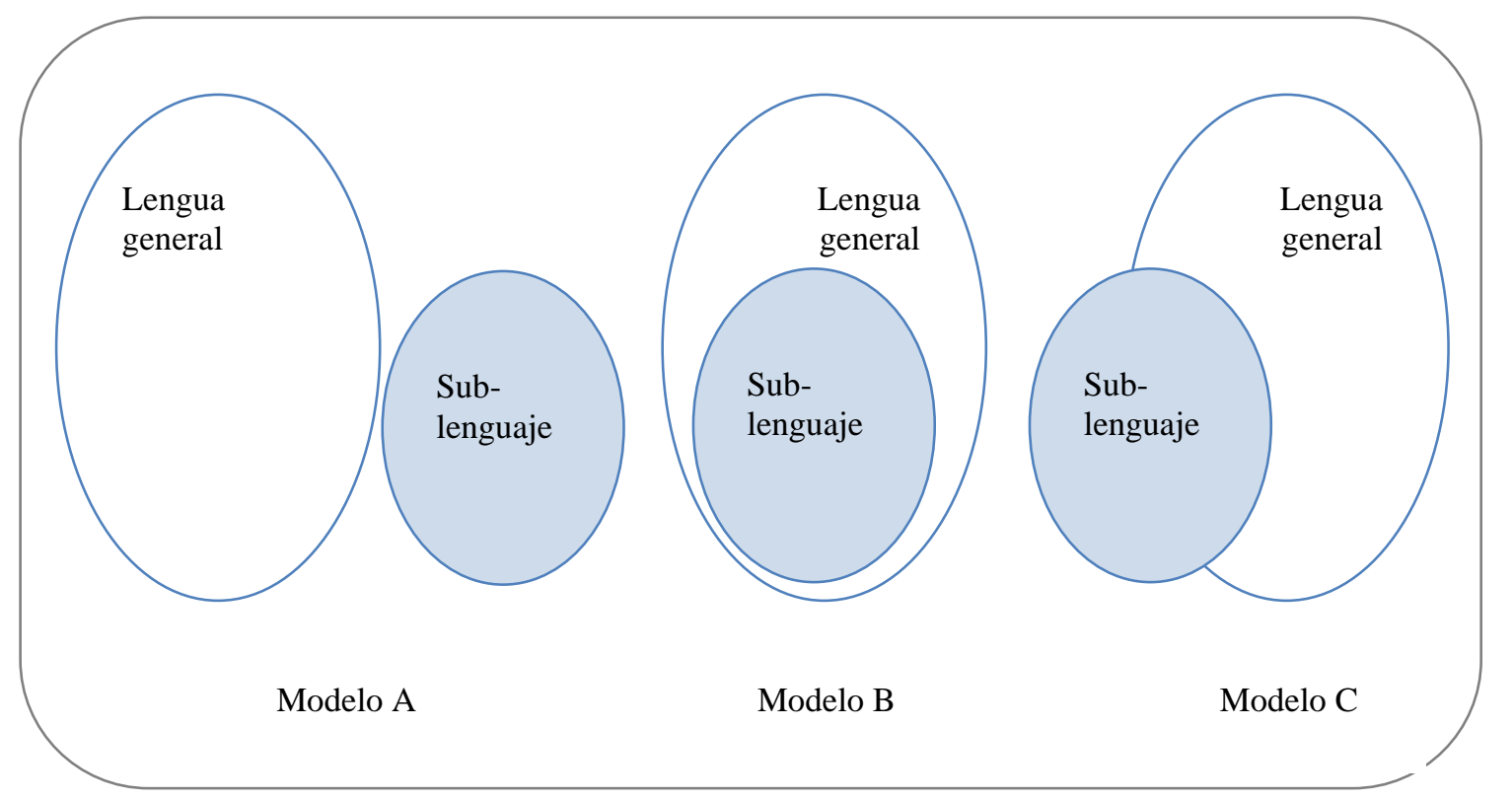

Figura 1. Comparación de las distintas propuestas conceptuales sobre las lenguas de especialidad

de K. Ahmad et alii (1995). Fuente: Pérez (2002) y García Antuña (2011).

Recientemente, desde una perspectiva variacionista y partiendo del concepto de lengua

histórica de Coseriu y de la tipología de la variación de Casas Gómez ${ }^{5}$ (2003, cf.

También Casas Gómez y Escoriza Morera 2009), García Antuña (2011: 213 y ss.)

ofrece un esquema alternativo, tanto desde el punto de vista gráfico como terminológico, al considerar que las lenguas de especialidad representan, más bien, un tipo de variación lingüística, que se incluye dentro de la clásica tipología variacionista

\footnotetext{
${ }^{5}$ Aunque, en un primer momento, Casas Gómez (1993 y 1997) incluye la distinción entre lenguaje común y lenguaje técnico dentro de los aspectos comprendidos por la variación diafásica, junto a la diferenciación entre estilos de lengua, entre lenguaje hablado y lenguaje escrito o diferencias de orden pragmático relacionadas con factores como el sexo, edad o generación, en un trabajo posterior aduce la existencia de una variación especializada independiente "que se encuentra a caballo entre la diafasía y la diastratía” (2003:570).
} 
entre diastratía y diafasía, por lo que su visión de los hechos se enmarcaría dentro del tercer modelo (C) de este gráfico modificado, en el que la lengua histórica comprende la “lengua” de especialidad como una lengua funcional:

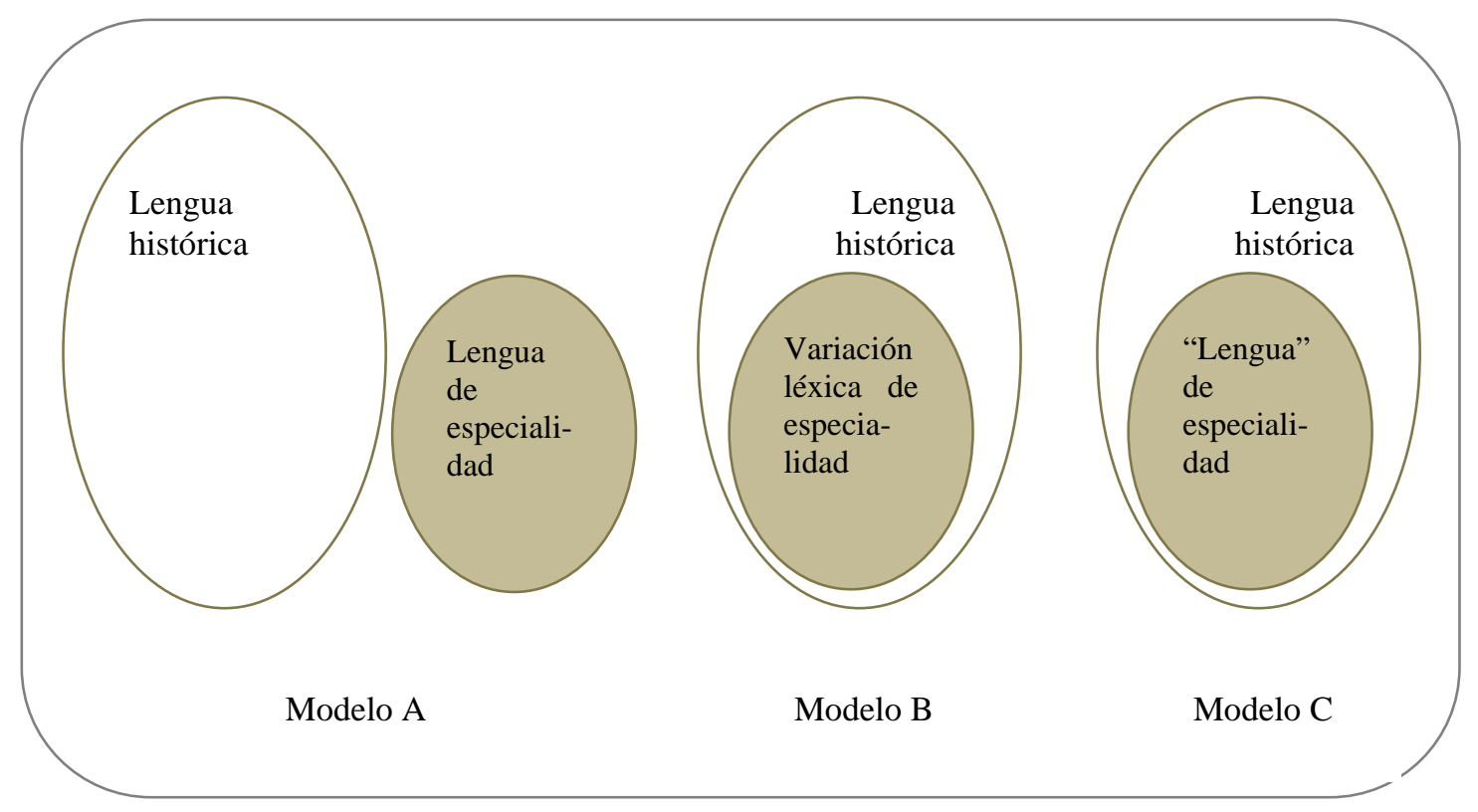

Figura 2. Comparación de las distintas propuestas conceptuales sobre las lenguas de especialidad de García Antuña. Fuente: García Antuña (2011: 187).

Pese a las diferencias mostradas por las diversas perspectivas expuestas, cabe preguntarse qué tienen en común todas ellas respecto a la caracterización de las lenguas de especialidad. A este respecto, Cabré (2004: 3) afirma que todas ellas coinciden en tratar las lenguas de especialidad como "producciones lingüísticas sobre temas relacionados con el saber descriptivo o procedural, sobre parcelas específicas del conocimiento”, por lo que, desde esta óptica, “todas las áreas científicas, tecnológicas o profesionales serían ámbitos de comunicación especializada”.

Independientemente de la noción de lengua de especialidad que se adopte, parece existir cierto consenso en reservar la denominación de lenguas con fines específicos (LFE) para el campo de la didáctica de lenguas. Así, para Cabré y Gómez de Enterría (2006: 12), las lenguas de especialidad son subsistemas de recursos específicos, lingüísticos y no lingüísticos, usados en contextos que se consideran especializados por sus condiciones comunicativas, en tanto que las lenguas con fines específicos constituyen el mismo conjunto de recursos, aunque desde el punto de vista del análisis de su uso en "ámbitos 
temáticos-funcionales precisos” ${ }^{\prime 6}$ y de su proceso de enseñanza-aprendizaje. Esto quiere decir que en las lenguas de especialidad se impone la especificidad de los recursos frente a la especificidad de la situación y/o función comunicativa que predomina en las LFE, de ahí que ambas autoras releguen la etiqueta de LFE al área de la enseñanza de lenguas. Para Bhatia (2008: 160), el principal objetivo de las LFE es la enseñanza y el aprendizaje de lenguas en contextos específicos, profesionales y académicos, motivo por el cual se ha ido paulatinamente ampliando el campo de acción de las LFE de la descripción de los recursos lingüísticos ${ }^{7}$ a la consideración del contexto, pues “ignorar cualquier aspecto del contexto del especialista puede crear problemas interculturales o interdisciplinares, algunos de los cuales pueden llegar a transformarse en potenciales obstáculos para un resultado comunicativo pragmáticamente exitoso”. Finalmente, Martín Peris (2007) ubica las lenguas de especialidad en el marco de la L1 dado que, además de la base temática, presentan características formales propias, y su número es relativamente reducido y fácil de establecer, pues están integradas por especialidades más o menos permanentes (Derecho, Medicina, Matemáticas, Física, Geografía, Lingüística, etc.). El marco de las LFE, en cambio, es la L2/LE, puesto que predomina la base discursiva sobre la temática, los usos sociales sobre las características formales y su número es más difícil de delimitar por su mayor cantidad y heterogeneidad. Las lenguas de especialidad, vistas de ese modo, representan, por tanto, un recurso al servicio de las LFE.

\section{Las lenguas profesionales y académicas}

Según el Diccionario de términos clave de ELE del Centro Virtual Cervantes, LFE hace referencia a "los procesos de enseñanza-aprendizaje que facilitan el dominio de la

\footnotetext{
${ }^{6}$ Con relación a esta idea, Gómez de Enterría (2006: 52; 2009: 49) afirma que "no se trata tanto de enseñar una lengua de especialidad, sino de hacer una inmersión en un discurso especializado concreto, el de la lengua propia de una situación precisa, con un uso puntual y en un ámbito profesional determinado" (cf. también Moirand 1994: 79).

7 "La adquisición de este tipo de competencia especializada (por ejemplo, la competencia de un especialista) no se basa solo en el uso de la lengua y de otros recursos semióticos, sino que también, en una buena comprensión de las restricciones disciplinares o institucionales específicas que operan de manera invariable sobre los géneros especializados” (Bhatia 2008: 160).
} 
comunicación especializada, esto es, la lengua que utilizan los profesionales que trabajan en un determinado contexto laboral o los expertos que desarrollan su actividad en una disciplina académica concreta”; según Hutchinson y Waters (1987: 21), es el enfoque de la enseñanza de lenguas que tiene como meta satisfacer las necesidades de comunicación de un grupo específico de aprendices. Ambas definiciones recogen las clasificaciones, restringida y amplia (respectivamente), que se observa en la literatura sobre el tema. En la primera, tienen cabida solo los fines profesionales y los fines académicos, en tanto que en la segunda se incluyen tantos fines específicos como grupos específicos de discentes podamos establecer. Así, en los últimos años la denominación fines o propósitos específicos, además de aplicarse a los profesionales y académicos, se extiende a la enseñanza de la lengua a inmigrantes en contextos escolares obligatorios (niños y adolescentes), la enseñanza de la lengua a inmigrantes adultos y la enseñanza de la lengua a niños ${ }^{8}$. Esta disparidad de criterios a la hora de concretar las clases de propósitos específicos deriva, en opinión de algunos (cf. Widdowson 1983: 5-7, Aguirre Beltrán 1998: 14-15), de la confusión entre finalidad y fines específicos. La finalidad conlleva la selección de temas y actividades en función del tipo o perfil del alumnado: niños, adolescentes, inmigrantes, etc., es decir, atendiendo a la finalidad hay tantos "fines" como grupos podamos establecer. Los fines específicos se orientan hacia el desarrollo de la competencia restringida (especializada) para desenvolverse en determinados contextos y realizar las tareas propias de esos contextos, es decir, los fines específicos se circunscriben a los propósitos académicos y profesionales. La tipología de fines específicos que se estableció inicialmente para la lengua inglesa distinguía cuatro categorías (Hutchinson y Waters 1987: 16): ESP (English for Specific Purposes), EAP (English for Academic Purposes), EST (English for Science \& Techology) y EOP (English for Occupational Purposes). En la actualidad, en Estados Unidos los fines específicos se dividen en tres grandes grupos: académicos (generales y por especialidades), profesionales (negocios, servicios sociales y tecnología) y vocacional (formación laboral y lingüística) (Robinson 1991: 17); en el

\footnotetext{
${ }^{8}$ Un ejemplo de ello puede verse en la obra fundamental de J. Sánchez Lobato e I. Santos Gargallo, Vademécum para la formación de profesores, publicado por la editorial SGEL en 2004, en donde encontramos diversos capítulos sobre la enseñanza de ELE en función del perfil del alumno, agrupados bajo denominación genérica de “La enseñanza del español con fines específicos” (pp. 1108-1302).
} 
Reino Unido se subsume EST (English for Science \& Techology) a ESP (English for Specific Purposes), que se mantiene junto con EAP (English for Academic Purposes) y EOP (English for Occupational Purposes) (Hutchinson y Waters 1987: 16; Aguirre Beltrán 1998: 15).

Resulta difícil determinar el número y las clases de propósitos específicos, pues estamos ante clasificaciones orientadas al mercado en función de la evolución y demanda del entorno (Aguirre Beltrán, 1998: 15). Esto último ha motivado que investigadores del tema prefieran utilizar las etiquetas de “español con fines profesionales” y “enseñanza del español lengua de especialidad” (Gómez de Enterría 2009: 14-15) o “lenguas profesionales y académicas”9 (Alcazaz Varó 2000, Alcaráz Varó et alii 2007) cuando se trata del proceso de enseñanza-aprendizaje de las lenguas de especialidad en contextos laborales o de formación. Los objetivos y finalidades de profesionales y estudiantes universitarios que solicitan este tipo de cursos son de índole muy diversa a las necesidades específicas de niños o inmigrantes (Rodríguez-Piñero Alcalá 2010), por lo que, a nuestro entender, los fines específicos se restringen a los propósitos académicos y profesionales. La razón para considerar los fines académicos juntos con los profesionales obedece al hecho de que no podemos olvidar que las lenguas de especialidad, como ha sido señalado por Alcaraz Varó (2007: 6-7), “[...] son lenguas profesionales, pero también son académicas porque antes de haber sido utilizadas en cada ambiente profesional, fueron enseñadas y aprendidas en la Universidad”. Las principales especialidades demandadas, en el caso de la lengua española, se circunscriben a los ámbitos jurídico, de los negocios, del turismo, de la diplomacia, de las ciencias de la salud y del medio ambiente (Gómez de Enterría 2009: 63-67). En cuanto a la lengua inglesa, después de la Segunda Guerra mundial, empezó a tener lugar el cambio del idioma alemán al inglés como la lingua franca instrumental dominante en la ciencia, la tecnología y los negocios. En la década de 1960, la expansión del inglés como lengua global en contextos académicos y profesionales se convertía en un hecho, por lo que todas las áreas de conocimiento y profesiones son requeridas en la enseñanza del inglés profesional y académico (IPA).

\footnotetext{
${ }^{9}$ Alcaraz Varó (2000) se decanta a favor de tal denominación antes y en contra de la de "fines específicos” porque cualquier uso que podemos hacer de una lengua siempre será específico y siempre servirá a un propósito.
} 


\subsection{Lenguas para fines profesionales (LFP)}

El principal objetivo que se propone la enseñanza de lenguas con fines profesionales (LFP) es el de proporcionar la competencia comunicativa necesaria para desenvolverse en diferentes contextos profesionales:

\footnotetext{
"Enfoque del proceso de enseñanza y aprendizaje que tiene como propósito mejorar las capacidades de comprensión y expresión que se requieren para desenvolverse en un determinado campo de actividad profesional” (Aguirre Beltrán 2004: 1116).
}

Los cursos formativos pueden tener un objetivo estándar (español para los negocios, inglés para el turismo...) o unos objetivos muy precisos, esto es, cursos diseñados “a la carta” para satisfacer necesidades comunicativas muy concretas en la lengua de especialidad (inglés para ejecutivos especialistas en capital de riesgo, inglés para expertos en turismo del bienestar...) (Gómez de Enterría 2009: 67). En el diseño de los cursos, se habrá de tener en cuenta, por tanto, el colectivo al que van dirigidos, el tema del que tratan y la finalidad de la comunicación que se persigue (Cabré y Gómez de Enterría 2006: 56-57, Gómez de Enterría 2009: 67).

Toda situación comunicativa especializada conlleva que se tengan en consideración los procesos de comunicación, tanto verbal como no verbal, la incorporación de las múltiples formas de las TICs, así como el contexto de internacionalización donde tiene lugar el intercambio comunicativo y que implica un conocimiento de las diferencias culturales sobre usos y costumbres de la comunidad de habla y de las normas de actuación de la cultura empresarial y de la cultura corporativa. En este sentido, es evidente, como señala Aguirre Beltrán (2001: 36), que “el nivel de competencia o capacidad y las técnicas concretas quedarían establecidas a partir del análisis de la situación meta en la que, en función del cargo y de las responsabilidades, deban desenvolverse". Es obvio que los profesionales, en las diversas organizaciones empresariales e instituciones, participan constantemente en situaciones comunicativas complejas (ya sean orales, escritas o mixtas), y en interacciones transaccionales o personales, que requieren de fluidez y eficacia así como del dominio de cualquier canal interactivo (cara a cara, por teléfono, por vídeo o tele conferencia, etc.). Pero también son necesarios en el desempeño de su ejercicio los intercambios para transmitir órdenes, 
recordar obligaciones y funciones, orientar o consultar, controlar actividades y conductas, gestionar información procedente de distintos soportes, etc. El planteamiento didáctico debe dirigirse hacia la adquisición de las competencias y destrezas comunicativas que hay que desplegar en un contexto determinado en el marco del ámbito especializado. Estas capacidades, habilidades y técnicas de comunicación implican un conocimiento de la lengua meta (vocabulario, estructuras gramaticales, contenidos fonéticos, expresión oral y comunicación no verbal), conocimiento de la “cultura” científica o sectorial-profesional a la que pertenece la lengua de especialidad y de la cultura corporativa o de la organización, así como de los usos y costumbres culturales de la comunidad de habla (Aguirre Beltrán 2001: 36 y 2004: 1116; Gómez de Enterría 2009: 72-74). En este tipo de enseñanza, cobra aún mayor relevancia el manejo de materiales auténticos. En este sentido, Cabré (1993: 164 y 166) y Gómez de Enterría (2009: 52-53) distinguen entre textos (científicos, técnicos y profesionales) y documentos. Pese a que el discurso científico, técnico y profesional “[...] sólo actúa como tal en el seno de la propia ciencia, técnica o de la profesión, sin olvidar al mismo tiempo que la denominación 'discurso científico, técnico o profesional’ no es más que una manera cómoda de designar una amplia variedad de discursos que se producen en esos contextos”, se suele observar una serie de características generales propias (Gómez de Enterría 2009: 52):

Se estructuran en párrafos breves y frases cortas.

Empleo de la primera persona del plural, que indica la presencia de un equipo.

Empleo frecuente de la voz pasiva.

Empleo frecuente de los tiempos verbales de presente.

Importancia de los sintagmas nominales (frecuentes nominalizaciones).

Inclusión de recuadros con datos o anotaciones complementarias.

Pueden presentar citas en las que se documentan.

Pueden presentar información gráfica adicional.

Pueden ofrecer un glosario con los términos técnicos empelados.

Pueden ofrecer una bibliografía o referencias bibliográficas. 
Los documentos son textos especializados con una estructura y codificación formal muy elaborada, tanto en lo que atañe al diseño como en lo que concierne a la expresión lingüística. Entre sus rasgos más destacados, Cabré (1993: 164 y 166) y Gómez de Enterría (2009: 53) señalan los siguientes:

Constituyen listas cerradas.

Suelen ser representativos de actos de habla.

No son espontáneos, sino que ofrecen una estructura determinada.

Poseen estructuras lingüísticas fijas (fraseología especializada, terminología, sintaxis).

Solo se dan en el plano escrito.

Poseen gran formalidad.

En consecuencia, las actividades programadas en el diseño de los cursos deberán estar basadas en el uso de ambos tipos de materiales, textos y documentos, del ámbito específico en cuestión.

\subsection{Lenguas para fines académicos (LFA)}

La meta que orienta la didáctica de lenguas con fines académicos (LFA) es la de facilitar a los aprendices la adquisición de destrezas que les permitan cumplir con éxito las tareas propias de los ámbitos universitarios ${ }^{10}$, es decir, la adquisición de la competencia requerida en la comunicación académica, entendida esta no solo como la lengua de especialidad de la comunidad científica, sino también como el “código oral y escrito que utilizan docentes y estudiantes en ámbitos universitarios para presentar, discutir y evaluar información de carácter científico” (Vázquez 2004: 1129). El estudiante universitario debe ser capaz de producir distintos tipos de textos (exámenes,

\footnotetext{
${ }^{10}$ Los fines académicos se ciñen a la esfera universitaria, aunque hay autores que extienden su campo de acción a la enseñanza de la lengua en contextos escolares obligatorios (Educación Primaria, Educación Secundaria Obligatoria y Bachillerato) (véase Pastor Cesteros 2006). No obstante, para este último tipo de didáctica -que guarda relevantes diferencias en cuanto al proceso de enseñanza-aprendizaje, la motivación de los discentes, el contexto didáctico, etc.- es preferible utilizar la denominación de lengua de instrucción (ing. training language) (cf. Villalba y Hernández 2004).
} 
reseña, trabajo, ensayos, informes, memoria, tesina, tesis, ponencias, monografías, etc.) y comprender los textos manejados en las diversas materias (clases magistrales, exposiciones, conferencias, artículos científicos, monografías, debates, etc.), esto es, debe poder participar en las diferentes tipologías de clases y actividades académicas de la vida universitaria. La principal causa de la aparición de este campo de la Lingüística aplicada son los programas de movilidad europea (ERASMUS ${ }^{11}$ ) de docentes y estudiantes. En el transcurso de los años, el perfil típico de movilidad ha ido variando, pues ya no son solamente estudiantes de las distintas Filologías los que acceden a dichos programas, sino universitarios de todas las titulaciones que aspiran a estudiar no solo la lengua meta, sino en la lengua meta (Vázquez 2006: 133) ${ }^{12}$. Independientemente de la lengua de que se trate, el discurso académico posee características propias en cuanto a la manera de organizar y estructurar la información, la intervención y alternancia de turnos de los interlocutores, y en el registro y estilo en cada ocasión o situación comunicativa. Difiere, además, de una lengua a otra y, a su vez, en cada sistema educativo, en la actividad docente y en el modo en que tiene lugar la comunicación en el aula. En su obra El lenguaje como cultura, Bernárdez (2008: 67-69) efectúa una comparación entre los discursos académicos románico, oriental y anglosajón: en el románico, se observa la presencia de “digresiones más o menos extensas, más o menos alejadas de la línea argumental básica”, lo que implica un aumento en el número de referencias bibliográficas, culturales y científicas; el oriental hace una aproximación indirecta al tema, empezando por un tema que en apariencia puede parecer estar alejado del

${ }^{11}$ El programa ERASMUS, abreviatura procedente de EuRopean Community Action Scheme for the Mobility of University Students (Plan de Acción de la Comunidad Europea para la Movilidad de Estudiantes Universitarios), es un programa de movilidad, perteneciente, a su vez, al Programa de Aprendizaje Permanente de la Comisión Europea, que tiene como objetivo atender a las necesidades de enseñanza y aprendizaje de todos los participantes en la educación superior formal y en la formación profesional de grado superior, cualquiera que sea la duración de la carrera o cualificación, incluidos los estudios de doctorado, así como a las instituciones que imparten este tipo de formación. Para más información, consúltese el portal de la OAPEE (Organismo Autónomo de Programas Educativos Europeos) <http://www.oapee.es/oapee/inicio/pap.html> [30/10/2012].

12 ADIEU (Akademischer Diskurs in der europäischen Union) es un proyecto lingüístico-intercultural, coordinado por esta lingüista, cuyo objetivo principal consiste en desarrollar materiales para estudiantes de nivel universitario que deseen cursar una parte de sus estudios en una universidad español. Los resultados de este proyecto se concretan en la publicación de los siguientes materiales en la editorial Edinumen: Actividades para la escritura académica, CD-Rom - Comprender en Español, El discurso académico oral. Guía didáctica para la comprensión auditiva y visual de clases magistrales, Guía didáctica del discurso académico escrito. ¿Cómo se escribe una monografía? 
principal, mientras que el anglosajón realiza una aproximación directa con un desarrollo argumentativo de carácter lineal, conduciendo al objetivo sin dilación ni rodeos:

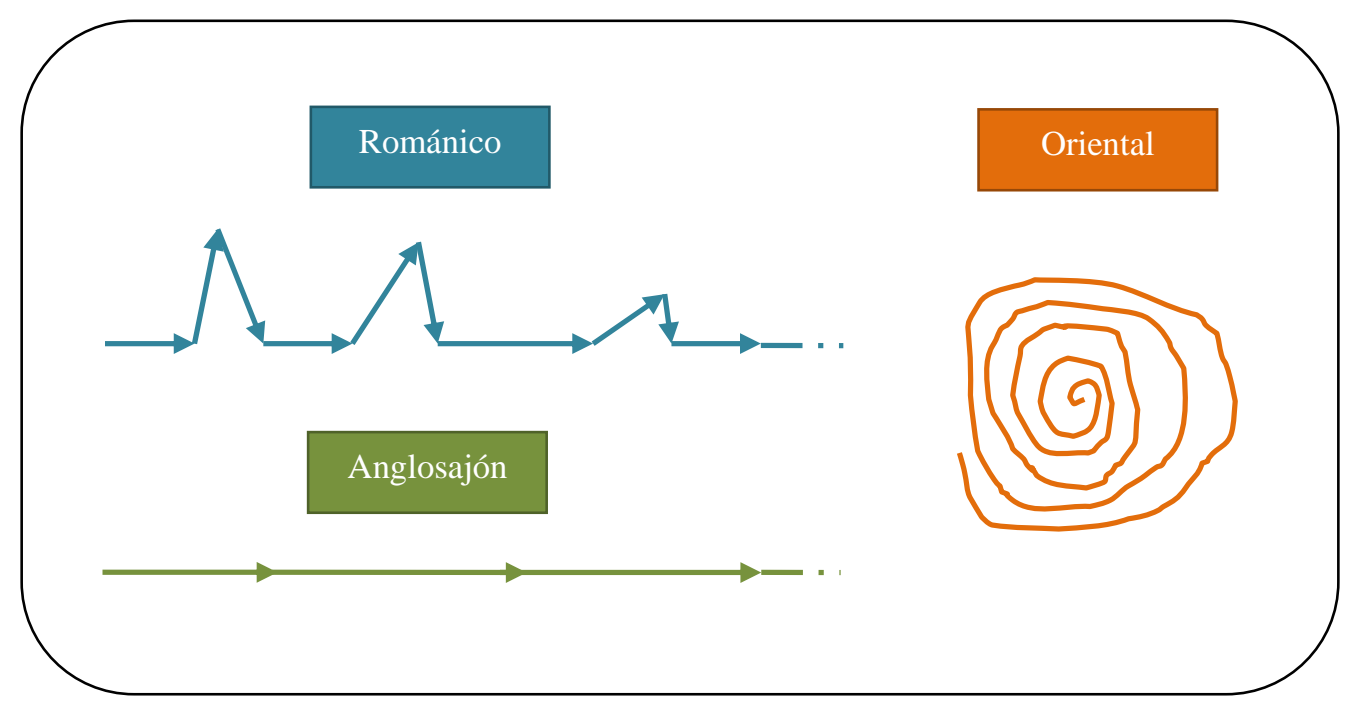

Figura 3.El discurso académico románico, oriental y anglosajón.

Fuente: Bernández (2008: 67-69).

El lenguaje académico está impregnado, igual que cualquier otra activad discursiva, de la cultura en que se crea, de ahí la necesidad de un planteamiento didáctico pragmático, que trate las cuestiones lingüísticas y los aspectos socioculturales (Pastor Cesteros 2006). Los problemas surgen por el desconocimiento de las tradiciones académicas, de la estructura y función de las clases y de las formas de evaluación. Algunos géneros académicos y los rituales asociados a ellos están explícitamente codificados (tesina, tesis, memoria de máster, proyecto, etc.), lo que conlleva también un aprendizaje específico:

\footnotetext{
“Se trata de un género textual que presenta características particulares de orden sociocultural, lingüístico y cognitivo, de manera que su tratamiento didáctico también presenta especificidades relevantes: la enseñanza-aprendizaje de textos académicos es una actividad sensiblemente diferente de la adquisición en la escuela de los usos formales (escrito, oral planificado) de la L1; y todavía más de la adquisición de los usos espontáneos de una L2” (Cassany y Castelló 1997, traducción de Pastor 2006).
}

Por consiguiente, la investigación en LFA, en opinión de Vázquez (2004: 1130), debe comprender las características de los géneros académicos, el diseño del currículo, el análisis de necesidades, los objetivos, los marcos teóricos, el enfoque metodológico, los entornos de aprendizaje, la evaluación, las estrategias comunicativas, la gramática del texto académico y 
el análisis de materiales y otros estudios relativos a este campo. El currículo, a su vez, debe satisfacer una serie de requisitos: debe trabajar con materiales auténticos que versen sobre contenidos específicos de las disciplinas particulares, debe focalizar el registro, la sintaxis y retórica propios de la disciplina y debe fomentar la autonomía mediante una enseñanza por tareas y con tándem con especialistas (Team-teaching), dado que se trata de un público adulto universitario (Flowerdew y Peacock 2001).

\section{La organización del proceso de enseñanza-aprendizaje de las LFE}

La didáctica de las LFE debe plantearse, igual que en el ámbito de la enseñanza de la competencia genérica, teniendo en cuenta los aspectos lingüísticos, pragmáticos y funcionales, es decir, dando cabida a contenidos gramaticales, discursivos, sociolingüísticos y socioculturales (Gómez de Enterría 2006: 53). En una investigación contrastiva entre la enseñanza del inglés de los negocios y del inglés con fines genéricos, Rosenberg (2004: 36) sintetiza las opiniones vertidas sobre un grupo de profesores en las siguientes semejanzas y diferencias:

\begin{tabular}{|c|c|c|}
\hline \multirow[t]{2}{*}{ Semejanzas } & \multicolumn{2}{|c|}{ Diferencias } \\
\hline & Inglés general & Inglés de los negocios \\
\hline $\begin{array}{ll}\checkmark & \text { la gramática y sus funciones } \\
\checkmark & \text { vocabulario general } \\
\checkmark & \text { ansiedad acerca de las } \\
& \text { capacidades } \\
\checkmark & \text { inglés de todos los días } \\
\checkmark & \text { charlar } \\
\checkmark & \text { vocabulario de viaje } \\
\checkmark & \text { inglés de supervivencia } \\
\checkmark & \text { acontecimientos } \\
& \text { actualidad de }\end{array}$ & $\begin{array}{ll}\checkmark & \text { actividad de tiempo libre } \\
\checkmark & \text { más libertad en la } \\
& \text { desviación del plan de } \\
\text { actuación } & \\
\checkmark & \text { más tiempo para los } \\
& \text { juegos } \\
\checkmark & \text { más relajado } \\
\checkmark & \text { canciones } \\
\checkmark & \text { literatura } \\
\checkmark & \text { habilidades de escritura }\end{array}$ & $\begin{array}{ll}\checkmark & \text { vocabulario } \\
& \text { especializado } \\
\checkmark & \text { relacionado con la } \\
& \text { motivación de empleo } \\
\checkmark & \text { enseñar a la } \\
& \text { negociación y la } \\
& \text { presentación } \\
\checkmark & \text { técnicas } \\
\checkmark & \text { los estudiantes están } \\
& \text { muy orientados hacia }\end{array}$ \\
\hline
\end{tabular}




\begin{tabular}{|l|c|c|}
\hline & en general & los objetivos \\
& $\checkmark$ acontecimiento social & $\checkmark$ menos lúdico \\
& $\checkmark$ correspondencia \\
& comercial \\
\hline
\end{tabular}

Tabla 1. Semejanzas y diferencias entre la enseñanza del inglés general y de los negocios.

Fuente: Rosenberg (2004: 36).

Otros autores, en cambio, no contemplan la separación entre los dos tipos de enseñanza, sino que consideran que la línea que marca la división entre ambos procesos didácticos se ha vuelto muy tenue, tal y como se desprende de esta significativa cita de Beugrande (1989):

\footnotetext{
"No LSP is composed exclusively of its own resources. Instead, every LSP overlaps heavily with at least one LGP and is free to use any part of the latter without express justification. One could not state the 'rules' which determine what parts of the grammar or lexicon of English may or may not appear in scientific English. Hence we have more of a continuum than a division between LSP and LGP”.
}

La enseñanza de LFE ha atravesado por diversas etapas desde sus comienzos en el mundo anglosajón ${ }^{13}$, las cuales Hutchinson y Waters (1987: 9; cf. asimismo Aguirre Beltrán 2004: 1112-1113) sintetizan en cinco fases:

Años 60: se examina el concepto de lengua de especialidad, su léxico y sus características gramaticales con vistas a la elaboración de materiales didácticos. El resultado de este análisis fue que no hay marcas distintivas o gramaticales especiales que no se den en la lengua general.

Años 70: se pasa del estudio de los rasgos léxicos y gramaticales al análisis del discurso de especialidad y de su aplicación al aula. Ello supuso la utilización en el

\footnotetext{
${ }^{13}$ En el panorama de la enseñanza de Español para Fines Específicos (EFE), suele situarse la década de los años ochenta como el momento en que instituciones académicas, editoriales y profesionales se interesan por el tema y tratan de satisfacer su demanda, que se vio incrementada a partir del ingreso de España en la Comunidad Económica Europea (actual Unión Europea) en 1986. Una revisión de los inicios y de la trayectoria recorrida por los estudios de EFE durante la última década puede consultarse en Felices Lago (2005).
} 
aula de modelos de textos reales y de marcadores del discurso.

Inicio años 80: se explora la situación meta y las características lingüísticas de esa situación. En esta etapa, se inicia la sistematización de la enseñanza teniendo en cuenta las necesidades de aprendizaje de los discentes y se adopta del currículo como elemento organizador del proceso de enseñanza-aprendizaje.

Años 80: el interés recae en las destrezas comunicativas necesarias y de las correspondientes estrategias para ser competentes en contextos variados.

Años 90: se pasa del análisis de la lengua y del proceso de enseñanza a un enfoque centrado en el aprendizaje (Learning-centred Approach), el aprendiz y sus capacidades para aprender.

Las principales diferencias existentes entre este nuevo modelo de enseñanza, centrado en el alumno y orientado hacia el proceso de aprendizaje, y el modelo tradicional, centrado en el docente y orientado hacia el proceso de enseñanza, quedan reflejadas en la siguiente tabla comparativa (Bará y Domingo 2005: 6-7):

\begin{tabular}{|l|l|lr|}
\hline & $\begin{array}{l}\text { Modelo orientado hacia la enseñanza } \\
\text { (contenidos) }\end{array}$ & $\begin{array}{l}\text { Modelo orientado hacia el aprendizaje } \\
\text { (procesos) }\end{array}$ \\
\hline Conocimiento & $\begin{array}{l}\text { El conocimiento se transfiere del } \\
\text { docente al estudiante. }\end{array}$ & $\begin{array}{l}\text { El conocimiento se construye } \\
\text { conjuntamente entre docente y estudiantes. }\end{array}$ \\
\hline Estudiantes & $\begin{array}{l}\text { Receptores “vacíos" que se llenan con } \\
\text { el conocimiento que les transfiere el } \\
\text { docente. }\end{array}$ & $\begin{array}{l}\text { Constructores activos, descubridores, } \\
\text { transformadores del conocimiento. }\end{array}$ \\
\hline Aprendizaje & $\begin{array}{l}\text { Fundamentalmente individual. } \\
\text { Requiere de motivación extrínseca. }\end{array}$ & $\begin{array}{l}\text { Fundamentalmente social. Requiere de } \\
\text { entorno que promueva la motivación } \\
\text { intrínseca. }\end{array}$ \\
\hline
\end{tabular}

\footnotetext{
${ }^{14}$ En este cuadro comparativo, se observa una serie de rasgos que son típicos de la teoría constructivista del aprendizaje. El constructivismo, que tiene su raíz en la teoría del desarrollo cognitivo de Piaget y en la teorías socioculturales de Vygotsky y Bruner, puede ser considerado como un paradigma en la docencia, que concibe el aprendizaje como un proceso complejo en cuya construcción participa activamente el alumno al aportar sus experiencias y conocimientos previos. El aprendiz participará de manera activa en ese proceso si es consciente del mismo y puede identificar las estrategias que él utiliza.
} 


\begin{tabular}{|c|c|c|}
\hline $\begin{array}{l}\text { Función del } \\
\text { docente }\end{array}$ & $\begin{array}{l}\text { Exponer el temario y calificar a los } \\
\text { estudiantes. }\end{array}$ & $\begin{array}{l}\text { Desarrollar competencias y habilidades de } \\
\text { los estudiantes. }\end{array}$ \\
\hline $\begin{array}{l}\text { Relaciones entre } \\
\text { los participantes }\end{array}$ & Impersonales. & Negociación personal. \\
\hline Contexto & Individualista y competitivo. & $\begin{array}{l}\text { Cooperativo en el aula y equipos } \\
\text { cooperativos de docentes. }\end{array}$ \\
\hline $\begin{array}{l}\text { Supuesto de } \\
\text { partida }\end{array}$ & Cualquier titulado puede enseñar. & $\begin{array}{l}\text { Enseñar es un proceso complejo que } \\
\text { requiere preparación. }\end{array}$ \\
\hline
\end{tabular}

Tabla 2. Semejanzas y diferencias entre los modelos de enseñanza. Fuente: Bará y Domingo (2005: 6-7)

El aprendizaje, desde este enfoque [centrado en el alumno], se considera un proceso y no un producto, y la adquisición de conocimientos se convierte en responsabilidad del aprendiente. Ello implica que los alumnos deben estar activamente involucrados en la planificación y gestión de su propio aprendizaje (Pierce McMahon 2011: 279).

Este cambio de orientación, producido a partir de los años 90, hace que el planteamiento didáctico se enfoque como un proceso de negociación constante entre los participantes (profesor y alumnos), de manera que la modificación en uno de los aspectos del diseño del curso conlleva la revisión y/o modificación del resto. Esta estrecha interrelación y dependencia de cada uno de los aspectos del currículo queda reflejada en el gráfico que Gómez de Enterría (2009: 76), en su manual sobre El español lengua de especialidad: enseñanza y aprendizaje, adapta de la propuesta de Dudley-Evans y St. John (1998: 121):

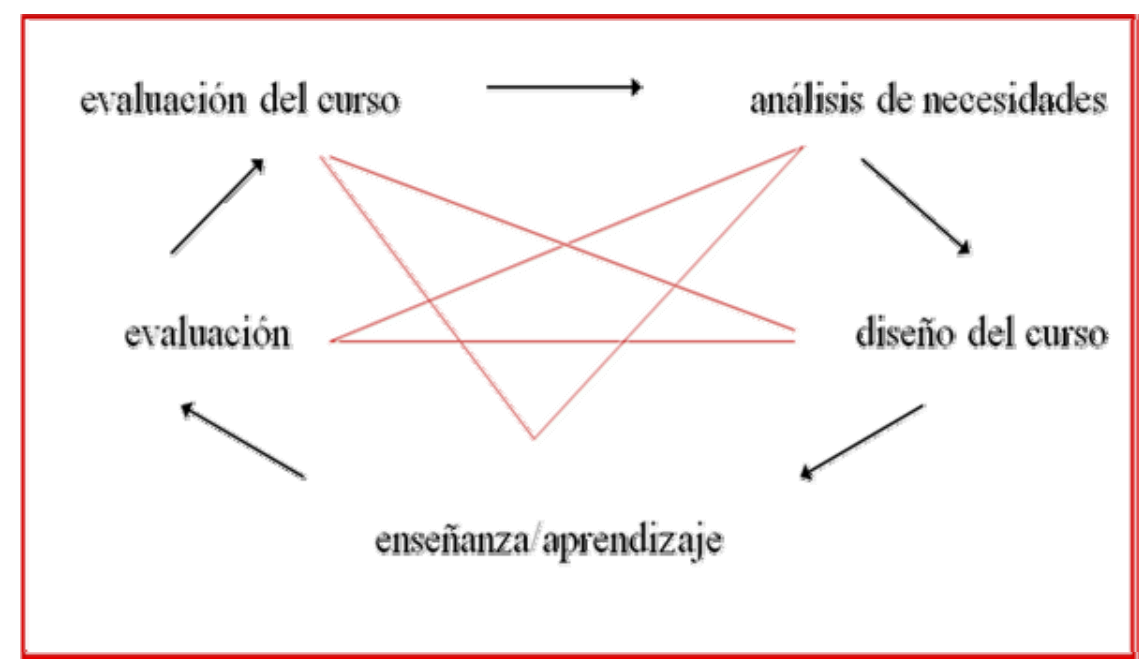

Figura 4. Interdependencia de los elementos del currículo.

Fuente: Dudley-Evans y St. John (1998: 121) y Gómez de Enterría (2009: 76). 
En la organización del proceso, hay que identificar la finalidad y la situación comunicativa, o sea, la competencia comunicativa restringida en el ámbito específico; fijar los objetivos a partir del análisis de las necesidades; establecer la metodología y el sistema de evaluación que se utilizará, y elaborar un plan de actuación que comprenda la programación, la secuenciación y temporalización de contenidos, que sean lo suficientemente flexibles como para adaptarse a las necesidades reales y a los ritmos de aprendizaje del grupo.

Antes de adentrarnos en la descripción de las principales técnicas de enseñanza, es conveniente señalar una serie de características generales, comunes para los procesos didácticos de todos los tipos específicos, académicos y profesionales. Nos encontramos ante una enseñanza especializada, orientada a unas metas en un campo específico, por lo que implica una determinada actitud hacia la lengua y establece una serie de temas, conceptos, nociones, textos y actividades concretos. Este tipo de cursos suelen, además, impartirse en un periodo de formación limitado y, a veces, con urgencia. Los alumnos son adultos en formación o profesionales del ámbito de especialidad y se requiere de cierta formación especializada del docente (Aguirre Beltrán 2004: 1121-1123). Finalmente, se fundamenta en el análisis de necesidades concretas y reales que demanda el grupo (Robinson 1991: 3), aspecto que junto con el conocimiento de la competencia comunicativa específica y de su experiencia previa en dicho campo específico conforman la base del proceso de enseñanza-aprendizaje de LFE. Según Aguirre Beltrán (1998: 17), el análisis de necesidades debe atender tanto a las exigencias de la institución/organismo/empresa que organiza el curso como al perfil del alumnado; debe tener en cuenta tanto las características de la lengua de especialidad en cuestión como de la situación-meta. Asimismo, debe satisfacer las necesidades de comunicación en relación con la lengua, los participantes en el acto comunicativo, los temas, las actividades y el marco de actuación, el canal de comunicación y el tipo de texto:

Lengua: estructura, funciones, nociones, niveles.

Interlocutores: colegas académicos, clientes, autoridades, empresarios, trabajadores.

Temas: investigación científica, contratación, bienes de consumo.

Marco de actuación: congresos, organismos oficiales, empresas de exportación. 
Canal: escrito, presencial, teléfono, videoconferencia, fax, email.

Tareas o actividades: presentar productos, tomar notas en una conferencia, redactar o leer informes técnicos.

Tipos y géneros de textos: documentos específicos, cartas, faxes, acuerdos entre empresas.

El análisis de necesidades, para Velázquez-Bellot (2004), debe ser selectivo (determina el área con la información pertinente: un departamento o servicio, un proyecto, una especialidad, etc.), situacional (contextos cotidianos laborales y culturales), cualitativo (los datos deben ser representativos del área), cuantitativo (suficientes para ser representativos) y “didactizable” (debe facilitar el diseño de materiales didácticos a partir de los datos recabados). Los instrumentos para detectar las necesidades los proporcionan cuestionarios, entrevistas, análisis de ofertas de trabajo, entrevistas con profesionales e instituciones del campo profesional, publicaciones, etc. (Aguirre Beltrán 2004: 1122; Velázquez-Bellot 2004).

\section{Métodos y técnicas de trabajo}

Todas las técnicas docentes que se proponen en este apartado se enmarcan en el modelo de enseñanza centrado en el alumno y orientado hacia el proceso ${ }^{15}$, dado que este enfoque incide en el aprendizaje permanente, en la adquisición de conocimientos y en el

\footnotetext{
${ }^{15}$ En este sentido, el Marco común europeo de referencia para las lenguas (2001: 9) adopta como marco de enseñanza-aprendizaje un enfoque que "se centra en la acción en la medida en que considera a los usuarios y alumnos que aprenden una lengua principalmente como agentes sociales, es decir, como miembros de una sociedad que tiene tareas (no sólo relacionadas con la lengua) que llevar a cabo en una serie determinada de circunstancias, en un entorno específico y dentro de un campo de acción concreto. Aunque los actos de habla se dan en actividades de lengua, estas actividades forman parte de un contexto social más amplio, que por sí solo puede otorgarles pleno sentido. Hablamos de "tareas" en la medida en que las acciones las realizan uno o más individuos utilizando estratégicamente sus competencias específicas para conseguir un resultado concreto. El enfoque basado en la acción, por lo tanto, también tiene en cuenta los recursos cognitivos, emocionales y volitivos, así como toda la serie de capacidades específicas que un individuo aplica como agente social”. Para una visión general de todas las técnicas didácticas que se enmarcan en dicho enfoque, resultan muy útiles las Guías rápidas sobre nuevas metodologías elaboradas por el Servicio de Innovación Educativa de la Universidad Politécnica de Madrid en $2008<\mathrm{http} / /$ innovacioneducativa.upm.es/formacionIE> y los documentos sobre estrategias y técnicas didácticas realizados por la Dirección de Investigación y Desarrollo Educativo del Instituto Tecnológico y Estudios Superiores de Monterrey <http://sitios.itesm.mx/va/diie/tecnicasdidacticas/>.
} 
fomento de las competencias y habilidades que los estudiantes deben desarrollar, y contempla las necesidades y capacidades de los distintos estudiantes. Según el Informe sobre innovación de la docencia en las Universidades Andaluzas (CIDUA 2005: 24), la formación de profesionales y ciudadanos competentes debe incluir el conjunto de conocimientos, actitudes y capacidades requeridas para su intervención autónoma y eficaz en la vida personal, social y profesional. Esta consideración debe extenderse asimismo a la formación lingüística y comunicativa en lenguas extranjeras de profesionales que deben desenvolverse en ámbitos internacionales. De hecho, la Unión Europea, en su recomendación sobre las Competencias claves para un aprendizaje permanente, establece como una competencia básica la comunicación en lengua extranjera $^{16}$ en diversos contextos sociales y culturales, como el educativo, el profesional, el familiar y el personal. Asimismo, el Marco común europeo de referencia para las lenguas (2001: 15) considera que las actividades de la lengua se encuentran contextualizadas dentro de unos ámbitos, que pueden ser muy diversos pero que, por motivos prácticos en relación con el aprendizaje de lenguas, se pueden clasificar de forma general en cuatro: el ámbito público, el ámbito personal, el ámbito educativo y el ámbito profesional. Es por ello que todas las metodologías docentes que favorecen la competencia básica de aprender a aprender ${ }^{17}$ y que conceden una especial atención a la manera de aprender del grupo y del individuo tienen cabida en el conjunto de estrategias didácticas que se propone para la formación en lenguas con fines académicos y profesionales. Junto a este motivo pedagógico, la adopción de todos estos métodos de

\footnotetext{
16 "La comunicación en lenguas extranjeras [...] se basa en la habilidad para comprender, expresar e interpretar conceptos, pensamientos, sentimientos, hechos y opiniones de forma oral y escrita (escuchar, hablar, leer y escribir) en una determinada serie de contextos sociales y culturales (como la educación y la formación, la vida privada y profesional y el ocio) de acuerdo con los deseos o las necesidades de cada cual” (Comisión Europea 2006: 7, la cursiva es nuestra).

${ }^{17}$ La Comisión Europea define esta competencia en el citado documento como "la habilidad para iniciar el aprendizaje y persistir en él, para organizar su propio aprendizaje y gestionar el tiempo y la información eficazmente, ya sea individualmente o en grupos. Esta competencia conlleva ser consciente del propio proceso de aprendizaje y de las necesidades de aprendizaje de cada uno, determinar las oportunidades disponibles y ser capaz de superar los obstáculos con el fin de culminar el aprendizaje con éxito. Dicha competencia significa adquirir, procesar y asimilar nuevos conocimientos y capacidades, así como buscar orientaciones y hacer uso de ellas. El hecho de "aprender a aprender" hace que los alumnos se apoyen en experiencias vitales y de aprendizaje anteriores con el fin de utilizar y aplicar los nuevos conocimientos y capacidades en muy diversos contextos, como los de la vida privada y profesional y la educación y formación. La motivación y la confianza son cruciales para la adquisición de esta competencia” (Comisión Europea 2006: 10, la cursiva es nuestra).
} 
trabajo también se fundamenta en el hecho de que la mayoría de ellos constituyen actividades que frecuentemente desempeñan los profesionales del campo específico. En el capítulo del Vademécum para la formación de profesores dedicado a la enseñanza del español con fines profesionales, B. Aguirre Beltrán (2004: 1123-1126) expone que la simulación global, los proyectos, las tareas, las presentaciones orales y los estudios de casos constituyen las principales técnicas didácticas. A este grupo habría, además, que añadirse otros métodos didácticos que igualmente favorecen el modelo de enseñanza orientado hacia los procesos, como son el aprendizaje cooperativo y el aprendizaje basado en problemas.

\subsection{La simulación global}

La simulación global (SG), como técnica didáctica, se propone la reconstrucción en el aula de los elementos que configuran una situación comunicativa en un ámbito específico. En su monografía sobre la enseñanza de los lenguajes de especialidad, Cabré y Gómez de Enterría (2006: 79) sostienen que la SG constituye una valiosa metodología docente, dado que "el soporte contextual de la realidad profesional permite una puesta en práctica de los discursos especializados insertos en el funcionamiento de la comunicación”. Para ambas autoras (2006: 81), a través de la SG es posible realizar tareas simultáneas encaminadas a enseñar y practicar todos los aspectos de la comunicación especializada en los contextos profesionales, incluidos los internacionales. Para que tenga éxito, es necesario una planificación exhaustiva en la que hay que gestionar el espacio del aula, organizar su estructura, establecer el plan de actuación, fijar las normas de recogida de la información, sentar las reglas del juego, disponer los papeles o roles que asumirán los discentes, trabajar con textos auténticos, utilizar las TICs que se emplean con mayor frecuencia, etc. La evaluación es continua y compartida, haciendo el aprendiz un seguimiento de su progreso en un dossier y participando en su propia valoración y en la de sus compañeros. Como metodología docente, son numerosas las ventajas que ofrecen Cabré y Gómez de Enterría (2006: 123-125) en su manual, entre las que sobresalen las siguientes (cf. asimismo Gómez de Enterría 2009: 118): 
rodríguez-piñero: metáfora 78

Favorece la participación activa de los estudiantes-participantes en el proceso de aprendizaje.

Permite el uso espontáneo del lenguaje por parte de los participantes: no deben existir interrupciones explícitas por parte del profesor en la producción de los discursos de la simulación.

Facilita la aplicación de múltiples estrategias motivadoras.

Favorece la participación activa de los aprendices en la planificación de las tareas y actividades y en la posterior evaluación.

Permite acercar al aula a contextos profesionales reales en los que se produce el aprendizaje de la lengua de especialidad.

Plantea trabajos de documentación (revisión de documentos, manuales, informaciones de prensa, etc.) para que la simulación no pierda contacto con la realidad profesional.

Sitúa el aprendizaje en contextos reales en los que los aprendices se expresan de forma espontánea al emitir opiniones favorables/desfavorables, al plantear/resolver problemas técnicos, producir informes, etc.

Potencia el valor de la interculturalidad como factor positivo en las relaciones profesionales.

Facilita al profesor las tareas de evaluación al proporcionarle una valiosa observación del estado de la interlengua del aprendiz.

La SG constituye un método frecuentemente utilizado, con excelentes resultados, en el contexto educativo y de formación del entorno profesional en diversos ámbitos: aeronáutica, medicina (cirugía con láser, psiquiatría, etc.), instituciones internacionales, sostenibilidad medioambiental, planificación urbanística, ingeniería industrial, negocios y comercio y enseñanza de lenguas extranjeras (cf. Cabré y Gómez de Enterría 2006: 80), de ahí su relevancia para la enseñanza de lenguas con fines profesionales.

\subsection{El enfoque por tareas}

El enfoque por tareas, actualmente muy extendido en la enseñanza de lenguas extranjeras, tiene la tarea como unidad de diseño de la actividad didáctica. Implica a los aprendices en la comprensión, manipulación, producción e interacción en la lengua extranjera; su atención se centra más en el significado que en la forma. El aprendiz ocupa el centro de interés, tomando decisiones junto con el profesor sobre los objetivos, la planificación del programa y los propios resultados. Junto al concepto básico de tarea, entendida como tarea comunicativa y meta del trabajo en el aula, se encuentran aquellas denominadas tareas posibilitadoras o capacitadoras, cuyo objetivo es lograr que los alumnos dominen los contenidos lingüísticos (gramaticales, funcionales, etc.) necesarios para realizar las tareas comunicativas, pero que no poseen todas las características de 
estas, es decir, actúan como soporte para las tareas de comunicación (Estaire 2004). A estos dos tipos de tareas, se suma la tarea final, que supone la actividad de uso en la que consiste la globalidad de la tarea. A la hora de diseñar una tarea, es importante plantear un objetivo claro desde el principio, tener en cuenta la experiencia previa de aprendizaje, a la vez que proporcionar motivos para la interacción y comunicación, así como fomentar la resolución de problemas y conflictos por vías y con resultados diferentes, teniendo en cuenta que los resultados finales serán compartidos en forma de exposición. Una de las grandes ventajas que ofrece este método es que responsabiliza al estudiante de su propio aprendizaje y lo sumerge en el uso de la lengua de especialidad. Para Gómez de Enterría (2009), este enfoque, junto con la simulación global, constituyen los principales métodos de trabajo para la enseñanza de las lenguas de especialidad.

\subsection{El aprendizaje orientado a proyectos}

El aprendizaje orientado a proyectos, aprendizaje basado en proyectos o aprendizaje por proyectos (AOP) es una metodología de aprendizaje en la que los participantes, en pequeños grupos, planifican, crean y evalúan un proyecto que responda a las necesidades planteadas en una determinada situación, relacionada con la actividad profesional. Una de las ventajas del AOP es que desarrolla las siguientes capacidades (de Miguel 2006):

Análisis y síntesis.

Investigación.

Transferencia de conocimientos y procedimientos a otros contextos.

Pensamiento crítico.

Responsabilidad individual y grupal.

Manejo de diversas fuentes de información, expresión oral y escrita.

Trabajo en equipo.

Planificación y organización y toma de decisiones.

En su guía sobre el AOP, el Servicio de Innovación Educativa de la Universidad Complutense de Madrid (2008: 14) indica que el gran potencial de esta técnica estriba no solo en los aprendizajes conceptuales que logran los participantes, sino también en las habilidades y destrezas que han de poner en práctica para conseguir que el trabajo en 
equipo sea para todos lo más útil y enriquecedor posible. La labor del docente también ha de centrarse en orientar el trabajo en los equipos, apoyar en la distribución de roles y en la resolución de conflictos. El AOP exige en todo momento que el aprendiz esté activo, interactuando con sus compañeros, contrastando opiniones, ideas, teorías y aplicaciones para llegar a consensos fundamentados y justificados, etc. La reflexión sobre el conocimiento con el fin de generar nuevo conocimiento es un eje central de esta metodología. Los proyectos se pueden plantear en cualquier nivel y las actividades se adaptarán a los conocimientos de los alumnos, a la disponibilidad de material y al tiempo disponible. En su programación, hay que organizar una serie de pasos que van desde la elección del tema, que viene delimitado por los objetivos, por las disciplinas y métodos profesionales, la búsqueda de materiales y documentación, la distribución del trabajo individual y grupal y la organización de la información, hasta su maquetación y presentación. Este modelo de trabajo se ha extendido particularmente en el ámbito de las ingenierías a nivel mundial. Una aplicación de esta metodología de trabajo a la enseñanza del español con fines específicos puede encontrarse en la tesis de máster de Monge Cosín: La enseñanza/aprendizaje del Español como Lengua Extranjera para fines académicos: Área de Letras, realizada en 2007 en la Universidad de Alcalá.

\subsection{Presentaciones orales}

Esta técnica consiste en la presentación de un tema, lógicamente estructurado, en donde el recurso principal es el lenguaje oral, aunque también puede serlo un texto escrito. En este siglo en el que vivimos, se nos exige un completo dominio del discurso oral y resulta difícil evadirse de hablar en público, ya sea en el ámbito académico, social o profesional (frente a un grupo de colegas, presentación de un proyecto, de una empresa, de un producto, etc.). Todo ello implica unas técnicas y una preparación que en ningún caso suponen una tarea fácil (Sanz Álava 2001: 133). La exposición, además de proveer de estructura y organización a material desordenado, también favorece la extracción de los puntos importantes de una amplia gama de información. Constituye un método de trabajo fundamental en la enseñanza de la lengua con fines profesionales y académicos, ya que forma parte de la actividad cotidiana en numerosos contextos laborales y profesiones y permite ejercitar la comunicación no verbal de forma natural. En relación con la comunicación no verbal, la Dirección de Investigación y Desarrollo Educativo 
del Instituto Tecnológico y Estudios Superiores de Monterrey (DIDE-ITESM 2004) considera que la información deber presentarse de forma dinámica, para lo cual es importante tener en cuenta ciertas habilidades de comunicación:

Variación en la voz. Es preciso adecuar el volumen y la velocidad de la voz al tamaño del grupo y a las características físicas del contexto, cuidar la claridad en la pronunciación y articulación de las palabras, variar la entonación a partir del manejo de pausas y silencios para dar "color" a lo que se dice, etc.

Gestos y movimientos corporales. Es importante apoyar lo que se dice verbalmente con gestos y movimientos corporales que sean congruentes y enfaticen la información proporcionada. Asimismo, es conveniente no permanecer estático en un solo lugar durante el tiempo que dura la exposición, hay que desplazarse a lo largo del espacio físico en el que esta ocurre.

Contacto visual. Es una fuente de retroinformación importante para el ponente, ya que le permite verificar que los destinatarios están o no de acuerdo con lo que se está exponiendo, si la exposición es clara o confusa o si la presentación está resultando interesante o aburrida, etc.

Esta metodología docente puede utilizarse por sí sola como técnica didáctica o puede formar parte de uno de los enfoques anteriores; puede llevarse a cabo tanto de forma individual como en grupo. Integra todas las destrezas comunicativas, pues es necesario documentarse sobre el tema, seleccionar la información relevante, trasladarla de forma sintetizada a una plantilla de exposición, póster, o similar, explicar con algo más de profundidad los datos proporcionados, etc. Asimismo, fomenta el desarrollo del pensamiento crítico en la medida en que el manejo que se realice de la presentación de un tema conduzca a enjuiciar y valorar la información que se presenta. Para ello, el estudiante requiere aplicar un conjunto de procesos cognitivos superiores y complejos como analizar, sintetizar, evaluar, resolver problemas o tomar decisiones.

\subsection{El método de casos}

El método de casos, también llamado estudio o análisis de casos o aprendizaje basado en casos, es una técnica de aprendizaje activo que proporciona prácticas para analizar problemas reales en un contexto profesional, frecuentemente utilizada en la didáctica de numerosas lenguas de especialidad (Derecho, Economía, Medicina, etc.). Está considerada por Dinapoli y Algarra (2002: 234) como un método especialmente 
efectivo en la enseñanza de lenguas extranjeras. Los estudiantes aprenden sobre la base de experiencias y situaciones de la vida real, permitiéndoles así, construir su propio aprendizaje en un contexto que los aproxima a su entorno. Un caso representa situaciones complejas de la vida real planteadas de forma narrativa, a partir de datos que resultan ser esenciales para el proceso de análisis. Asopa y Beye (1997) lo definen como el "method of learning based on active participation and cooperative or democratic discussion of a situation”. El estudio de casos integra todas las destrezas comunicativas, permite comprobar las estrategias de resolución de problemas y facilita la práctica de estrategias de aprender a aprender, puesto que se apoyan en los conceptos, principios y procedimientos que se emplean en el campo específico. Los objetivos de esta estrategia didáctica son (UPV 2006):

1. Formar futuros profesionales capaces de encontrar para cada problema particular la solución experta, personal y adaptada al contexto social, humano y jurídico dado.

2. Trabajar desde un enfoque profesional los problemas de un dominio determinado. El enfoque profesional parte de un problema real, con sus elementos de confusión, a veces contradictorios, tal como en la realidad se dan, y se pide una descripción profesional, teóricamente bien fundada, comparando la situación concreta presentada con el modelo teórico, identificando las peculiaridades del caso, proponiendo estrategias de solución del mismo, y evaluando los resultados.

3. Crear contextos de aprendizaje que faciliten la construcción del conocimiento y favorezcan la verbalización, explicitación, el contraste y la reelaboración de las ideas y de los conocimientos.

Algunos autores, como Martínez y Musitu (1995), establecen tres categorías de casos, en función de las metas de aprendizaje que se persigan. A través de casos centrados en el estudio de descripciones, se pretende que los participantes analicen, identifiquen y describan los puntos claves constitutivos de la situación dada y puedan, asimismo, debatir y reflexionar con los compañeros las distintas perspectivas de abordar dicha situación (no se pide a los aprendices que valoren o generen soluciones, sino que se centren en el análisis del problema y de las variables que lo constituyen). Mediante los casos de resolución de problemas, se exige, tras un exhaustivo análisis de la situación dada, una valoración de la decisión tomada por el protagonista del caso o la propuesta de una solución alternativa a la ofrecida en el mismo. En los casos centrados en la aplicación de principios, la situación presentada requiere del análisis y selección de aquellos principios y normas que favorezcan su resolución. Con este tipo de casos se 
favorece el desarrollo del pensamiento deductivo, que supone partir de la generalidad de la situación e ir aplicando las premisas necesarias para llegar a las conclusiones que dan la respuesta más adecuada. Este método acentúa el proceso seguido por los estudiantes para la resolución del caso, más que en el producto final, y favorece el desarrollo de competencias, capacidades y actitudes tales como habilidades intelectuales, habilidades comunicativas y de relaciones interpersonales, habilidades de organización y gestión de la información, conocimientos generales para el aprendizaje, vinculados a la materia y vinculados al mundo profesional, capacidad para anticipar y evaluar el impacto de las decisiones tomadas, actitudes y valores del desarrollo profesional (autonomía, flexibilidad, etc.) y valores de compromiso personal (responsabilidad, iniciativa, etc.), habilidades para trabajar de forma autónoma y en grupo (SIE-UPM 2008c), a las que podríamos añadir otras competencias como la capacidad para generar nuevas ideas (creatividad), capacidad crítica y autocrítica, capacidad de análisis y síntesis o habilidades para la planificación y gestión del tiempo.

\subsection{El aprendizaje cooperativo}

El aprendizaje cooperativo consiste en un conjunto de procedimientos didácticos que parten de la organización de la clase en pequeños grupos mixtos y heterogéneos, donde los participantes trabajan conjuntamente de forma coordinada entre sí para resolver tareas académicas y profundizar en su propio aprendizaje. Cooperar significa trabajar juntos para alcanzar objetivos compartidos. Para L. Prieto (2008: 15), aprender cooperativamente "representa una ocasión privilegiada para alcanzar objetivos de aprendizaje muy diversos, no solo referidos a los contenidos, sino también orientados al desarrollo de habilidades y destrezas interpersonales, con claros beneficios para el aprendizaje de los alumnos”. Según Johnson, Johnson y Helubec (1999), son cinco los componentes esenciales del AC:

1. Interdependencia positiva, la cual existe cuando los estudiantes perciben un vínculo con sus compañeros de grupo de forma tal, que no pueden lograr el éxito sin ellos (y viceversa), coordinando sus esfuerzos con los de sus compañeros para poder completar una tarea, compartiendo recursos, proporcionando apoyo mutuo y celebrando juntos el éxito.

2. La interacción "cara a cara" o simultánea, dado que los estudiantes tienen que trabajar juntos, “aprender con otros” (Prieto 2008: 49), favoreciendo, de esta manera, que compartan 
conocimientos, recursos, ayuda o apoyo. Discutir sobre los distintos puntos de vista, sobre la manera de enfocar determinada actividad, explicar a los demás lo que cada uno va aprendiendo, etc. son acciones que se tienen que llevar a cabo con todos los miembros del equipo para poder lograr los objetivos previstos.

3. Responsabilidad individual, puesto que cada miembro, individualmente, tiene que asumir la responsabilidad de conseguir las metas que se le han asignado. Por tanto, realmente, cada persona es, y debe sentirse, responsable del resultado final del grupo. Este concepto sintoniza y complementa al de interdependencia positiva. La responsabilidad individual, en opinión de Prieto (2008: 45), “implica, por un lado, que cada uno sea responsable de contribuir de algún modo al aprendizaje y al éxito del grupo. Por otro se requiere que el estudiante individual sea capaz de demostrar públicamente su competencia”.

4. Habilidades sociales, tanto en lo referente al aprendizaje como también vinculadas a las relaciones entre los miembros, muy necesarias para el buen funcionamiento y armonía del grupo. Los roles que cada persona vaya ejerciendo en el equipo (líder, organizador, animador, el “pasota”, etc.), su aceptación o no por parte del resto de compañeros, la gestión que hagan de los posibles conflictos que surjan, el ambiente general que existe en el mismo, la comunicación precisa y sin ambigüedades, etc. son temas que los estudiantes tienen que aprender a manejar. Según Morales (2008), “saber trabajar en equipo es una competencia profesional que no se va aprender si no se ejercita y evalúa durante el proceso de enseñanza-aprendizaje”, por lo que su enseñanza y práctica debería ser obligada en todos los cursos de lenguas con fines específicos.

5. La autoevaluación del grupo, por la que los miembros del grupo reflexionan y discuten entre sí cuál es el nivel de logro de sus metas y del mantenimiento efectivo de relaciones de trabajo, identifican cuáles de las acciones de los miembros son útiles y cuáles no, y toman decisiones acerca de las acciones que deben continuar o cambiar.

Para el diseño de situaciones de aprendizaje cooperativo, es necesario definir los objetivos de enseñanza, planificar los materiales y recursos de enseñanza para promover la interdependencia positiva, explicar la tarea académica, estructurar la meta grupal, la valoración individual y la cooperación dentro del equipo, describir los criterios de éxito y las conductas deseadas, decidir el tamaño del grupo y asignar estudiantes a los grupos y roles para asegurar la interdependencia, gestionar el aula, proporcionar asistencia en todos los procesos y actividades, evaluar la calidad y cantidad del aprendizaje de los discentes, valorar el funcionamiento del grupo, etc. Entre los que han aplicado el aprendizaje cooperativo al campo de la enseñanza de segundas lenguas se encuentran, por ejemplo, Cassany (2004 y 2009) y Sanz Álava (2004). 


\subsection{El aprendizaje basado en problemas}

El aprendizaje basado en problemas (ABP) constituye tanto un enfoque educativo en su totalidad, como una técnica de enseñanza-aprendizaje, es decir, como una forma de trabajo que puede ser utilizada combinada con otras estrategias o técnicas didácticas. El camino que recorre el proceso de aprendizaje convencional se invierte al emplear el APB. Mientras que tradicionalmente primero se expone la información y posteriormente se busca su aplicación, en esta técnica primero se presenta el problema, se identifican las necesidades de aprendizaje, se busca la información necesaria y, finalmente, se regresa al problema. Es un método de trabajo centrado en el alumno (activo), en el que el aprendizaje se produce en pequeños grupos (de 5 a 8 miembros). El docente se convierte en facilitador, guía o tutor de ese proceso de aprendizaje y los problemas representan el foco para la organización del grupo, estimulando el aprendizaje y constituyendo un vehículo para el desarrollo de habilidades de resolución de problemas (cf. Barrows 1996). Su finalidad es el desarrollo integral del aprendiz, en donde es tan relevante la adquisición de conocimientos, como el desarrollo de competencias y destrezas, tales como habilidades de resolución de problemas, de toma de decisiones, de trabajo en equipo, destrezas y estrategias comunicativas (argumentación y presentación de la información), actitudes y valores (precisión, revisión, tolerancia, etc.) (de Miguel 2005), capacidad para el pensamiento crítico, habilidades de evaluación y autoevaluación, conciencia del propio aprendizaje o la identificación de problemas relevantes del entorno profesional (Prieto 2006). En el documento sobre esta técnica elaborado por la Dirección de Investigación y Desarrollo Educativo del Instituto Tecnológico y Estudios Superiores de Monterrey (DIDE-ITESM 2004), se exponen los objetivos que persigue el ABP:

Promover en el alumno la responsabilidad de su propio aprendizaje (aprendizaje autodirigido).

Desarrollar una base de conocimiento relevante caracterizada por profundidad y flexibilidad.

Desarrollar habilidades para la evaluación crítica y la adquisición de nuevos conocimientos con un compromiso de aprendizaje de por vida.

Desarrollar habilidades para las relaciones interpersonales.

Involucrar al alumno en un reto (problema, situación o tarea) con iniciativa y entusiasmo.

Desarrollar el razonamiento eficaz y creativo de acuerdo a una base de conocimiento integrada y flexible.

Verificar la existencia de objetivos de aprendizaje adecuados al nivel de desarrollo de los alumnos. 
Orientar la falta de conocimiento y habilidades de manera eficiente y eficaz hacia la búsqueda de la mejora.

Estimular el desarrollo del sentido de colaboración como un miembro de un equipo para alcanzar una meta común.

Entre los pasos que deben seguirse en el APB, Morales y Landa (2004) establecen los siguientes:

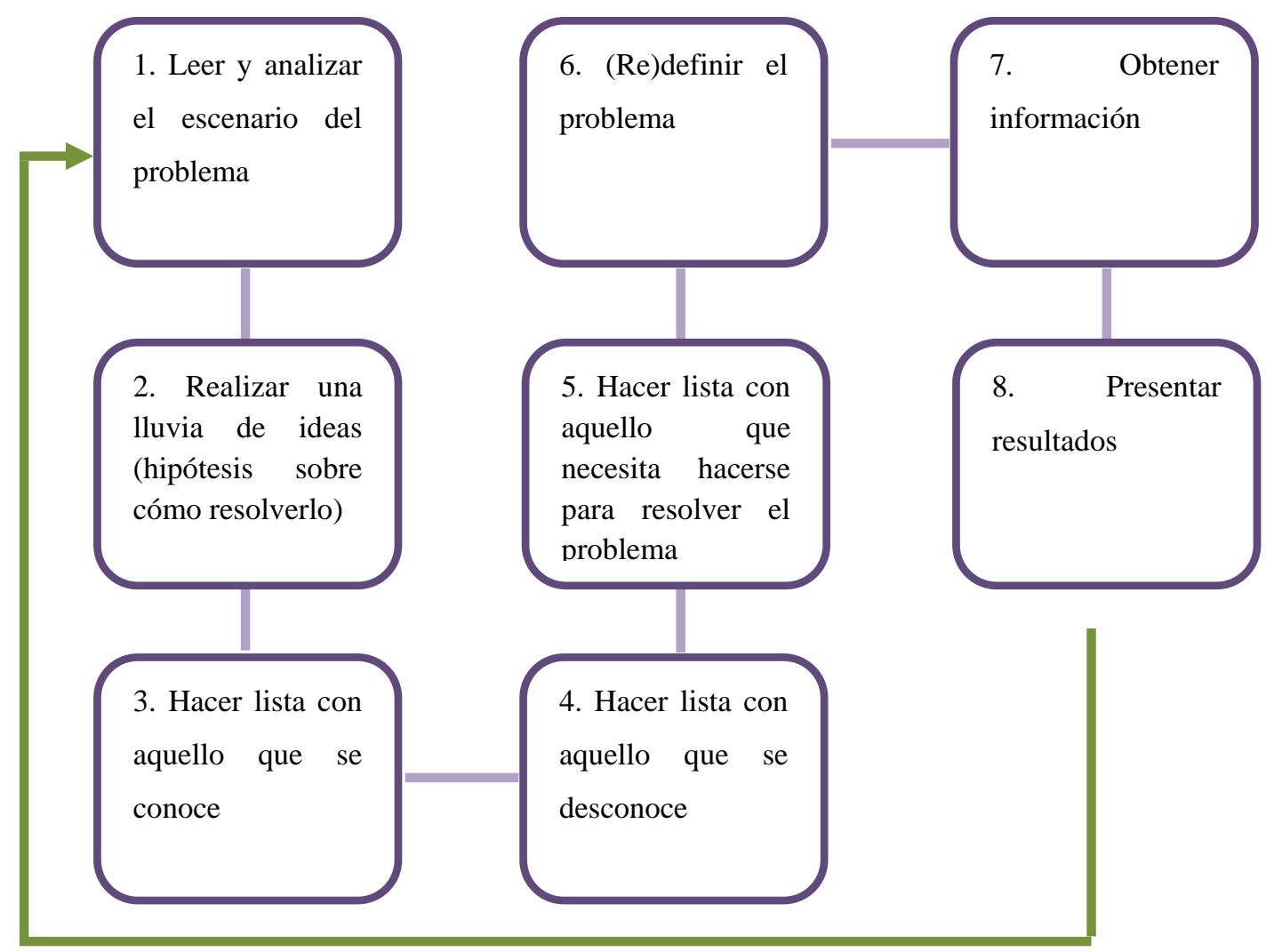

Figura 5. Pasos que deben seguirse en el ABP. Fuente: Morales y Landa (2004).

Es recomendable que, en general, una tarea de resolución de problemas se cierre con una actividad que ayude a revisar la información, los resultados obtenidos y los procesos involucrados. Las actividades de resolución de problemas se pueden considerar paradigmáticas del principio de aprender una lengua usándola de forma significativa. En efecto, el problema que se propone a los alumnos pretende que estos exploren la lengua, pongan en práctica estrategias y procedimientos, argumenten, analicen información e investiguen. Una aproximación a esta metodología en el marco de la enseñanza de lenguas extranjeras puede verse en Kosel (2002). 


\section{Conclusiones}

Independientemente de que se consideren las lenguas de especialidad como subconjuntos de recursos lingüísticos y pragmáticos o como una dimensión más de la variación lingüística, parece existir un relativo consenso a la hora de reservar la denominación de fines específicos para el área de la didáctica de lenguas. Desde sus inicios, los propósitos específicos han ido extendiendo su campo de acción hasta comprender la enseñanza de la lengua en contextos profesionales y académicos, pero también la enseñanza de esta a niños, adolescentes o inmigrantes, cuyas circunstancias y necesidades comunicativas varían mucho de las que puedan tener los estudiantes universitarios o los profesionales de un ámbito especializado. Aunque no se observa una separación tajante entre la enseñanza de la competencia genérica y la competencia específica, sí hallamos, desde este último ámbito, cierta predilección por una serie de técnicas didácticas basadas en métodos de trabajo que forman parte de la actividad profesional habitual, como la simulación global, el enfoque por tareas, el aprendizaje orientado a proyectos, las presentaciones orales, el método de casos, el aprendizaje cooperativo y el aprendizaje basado en problemas. Todas estas metodologías docentes se encuadran dentro del modelo de enseñanza centrado en el aprendiz y orientado hacia los procesos de aprendizaje, que además de fomentar la adquisición de conocimientos, favorecen el desarrollo de competencias y habilidades que son frecuentemente demandas en el desempeño del ejercicio profesional.

\section{Referencias bibliográficas}

Aguirre Beltrán, B. 1998. Enfoque, metodología y orientaciones didácticas en la enseñanza del español con fines específicos. La enseñanza del español para fines específicos, Carabela, 44. Madrid: SGEL, 5-29.

Aguirre Beltrán, B. 2001. El español para la comunicación profesional. Enfoques y orientaciones didácticas. Español para Fines Específicos. Actas del I Congreso Internacional de Español para Fines Específicos. Amsterdam, noviembre de 2000, Madrid: Ministerio de Educación, Cultura y Deporte, 34-43, http://cvc.cervantes.es/ensenanza/biblioteca_ele/ciefe/pdf/01/cvc_ciefe_01_0006.pdf.

Aguirre Beltrán, B. 2004. La enseñanza del español con fines profesionales. J. Sánchez 
Lobato e I. Santos Gargallo, dirs.), Vademécum para la formación de profesores, Madrid: SGEL, 1109-1128.

Ahmad, K., Martin, W., Hoelter, M. y Rogers, M. 1995. Aspects of Terminology Infrastructure in Europe: Volume 3 - Specialist Terms in General Language Dictionaries. POINTER Report. http://www.mcs.surrey.ac.uk.

Alcaraz Varó, E. 2000. El inglés profesional y académico, Madrid: Alianza.

Alcaraz Varó, E., Mateo Martínez, J. y Yus Ramos, F. (coord.) 2007. Las lenguas profesionales y académicas, Barcelona: Ariel.

Bará, J. y Domingo, J. 2005. Técnicas de Aprendizaje Cooperativo. Taller de formación desarrollado en la Universidad Autónoma de Madrid los días 28 y 29 de abril de 2005, http://www.uctemuco.cl/cedid/archivos/diplomado/sobre_aprendizaje_cooperativo.pdf

Barrows, H. S. 1996. Problem-based learning in medicine and beyond: A brief overview. New directions for teaching and learning, 68, 3-12.

Beaugrande, R. de 1987. Special Purpose Language and Linguistic Theory. LSP Newsletter, 10, 2, 2-11.

Beaugrande, R. 1989. Special purpose language as a complex system: The case of linguistics. C. Lauren \& M. Nordman (coord.), Special Language: From Humans to Thinking Machines, Philadelphia: Multilingual Matters, 3-29.

Bernárdez, E. 2008. El lenguaje como cultura, Madrid: Alianza.

Bhatia, V. 2008. Lenguas con Propósitos Específicos: Perspectivas cambiantes y nuevos desafíos. Signos, 41/67, 157-176. http://www.scielo.cl/pdf/signos/v41n67/a06.pdf

Cabré, T. 1993. La terminología. Teoría, metodología, aplicaciones, Barcelona: Antártida/ Empúries.

Cabré, T. 1999. La terminología: representación y comunicación. Elementos para una teoría de base comunicativa y otros artículos, Barcelona: Institut Universitari de Lingüística Aplicada de la Universitat Pompeu-Fabra.

Cabré, T. 2004. ¿Lenguajes especializados o lenguajes para propósitos específicos?. En A. van Hooft (coord.), Textos y discursos de especialidad: el español de los negocios. Revista Foro Hispánico, 26, 19-34. 
Cabré, T. y Gómez de Enterría, J. 2006. La enseñanza de los lenguajes de especialidad. La simulación global, Madrid: Gredos.

Cabré, T., Martorell, C., Castellà, J. M. y Martí, J. 2007. La caracterización lingüística del discurso de especialidad. En R. Mairal y otros (coord.), Aprendizaje de lenguas, uso de la lengua y modelación cognitiva: perspectivas aplicadas entre disciplinas. Actas del XXIV Congreso Internacional de AESLA, Madrid: UNED, AESLA, 851-857.

Casas Gómez, M. 1993. Consideraciones sobre la variación diafásica. Pragmalingüística 1, 94-124.

Casas Gómez, M. 1997. Diaphasiche Variation und Fachsprache. Zeitschrift für romanische Philologie 113.2, 173-189.

Casas Gómez, M. 2003. Hacia una tipología de la variación. F. Moreno Fernández, J. A. Samper Padilla, M. Vaquero, M. L. Gutiérrez Araus, C. Hernández Alonso y F. Gimeno Menéndez (coord.), Lengua, variación y contexto. Estudios dedicados a Humberto López Morales II, Madrid: Arco/Libros, 559-574.

Casas Gómez, M. y Escoriza Morera, L. 2009. Los conceptos de diastratía y diafasía desde la teoría lingüística y la sociolingüística variacionista. Estudios de lengua española: descripción, variación y uso. Homenaje a Humberto López Morales, Madrid: Iberoamericana/Vervuert, 151-178.

Cassany, D. 2004. Aprendizaje cooperativo para ELE. Actas del programa de formación para profesorado de español como lengua extranjera 2003-2004. Múnich: Instituto Cervantes de Múnich, 11-30.

Cassany, D. 2009. La cooperación en ELE: de la teoría a la práctica. Tinkuy. Boletín de Investigación y Debate, 11, 7-29.

Cassany, D. y Castelló, M. 1997. Textos académics. Articles, 13, 5-10.

Comisión Europea 2006. Competencias claves para el aprendizaje permanente. Un Marco de Referencia Europeo. Recomendación del Parlamento Europeo y del Consejo de 18 diciembre 2006 publicada en el Diario Oficial de la Unión Europea L 394 de 30 diciembre 2006, http://ec.europa.eu/dgs/education_culture/publ/pdf/ll-learning/keycomp_es.pdf.

Comisión para la innovación de la docencia en las Universidades Andaluzas 2005. 
Informe sobre innovación de la docencia en las Universidades Andaluzas, http://viceees.ujaen.es/files_viceees/CIDUA.pdf.

De Miguel, M. (coord.) 2006. Metodologías de enseñanza para el desarrollo de competencias. Orientaciones para el profesorado universitario ante el Espacio Europeo de Educación Superior, Madrid: Alianza.

Dinapoli, R. y Algarra, V. 2002. A case for dramatic scenarios in LSP. E. Hernández y L. sierra (coord.), Lenguas para fines específicos VII), Alcalá de Henares: Universidad de Alcalá, 233-236.

Dirección de Investigación y Desarrollo Educativo del Instituto Tecnológico y Estudios Superiores de Monterrey 2004. El Aprendizaje Basado en Problemas como técnica didáctica, http://www.ub.es/mercanti/abp.pdf.

Dudley-Evans, T. y St. John, M. J. 1998. Development in English for Specific Purposes. A multi-disciplinary approach, Camdridge: Cambridge University Press.

Estaire, S. 2004. La programación de unidades didácticas a través de tareas. RedEle. Revista Electrónica de didáctica de español como lengua extranjera 1, http://www.educacion.gob.es/dctm/redele/Material-RedEle/Revista/2004_01/2004_redELE_1_04Estaire.pdf?documentId=0901e72b80e06811.

Felices Lago, Á. 2005. El español para fines específicos y su desarrollo en España durante la última década. IDEAS FH-Heilbronn). Investigaciones y Estudios Hispánicos Aplicados 1, http://www.ideas-heilbronn.org/artic.htm.

Flowerdew, J. y Peacock, M. (coord.) 2001. Research Perspectives on English for Academic Purposes, Cambridge: Cambridge University Press.

García Antuña, M. 2011. La variación especializada: Caracterización terminológica del léxico específico de la piel. Tesis doctoral, Universidad de Cádiz.

Gómez de Enterría, J. 2006. Últimos enfoques en la enseñanza-aprendizaje del español con fines profesionales. En A. M. Cestero (coord.), Lingüística aplicada a la enseñanza de español como lengua extranjera: desarrollos recientes, Alcalá de Henares: Universidad, 47-60.

Gómez de Enterría, J. 2009. El español lengua de especialidad: enseñanza y aprendizaje, Madrid: Arco/Libros.

Hoffmann, L. 1998. Llenguatges d'especialitat. Selecció de textos, Barcelona: Institut Universitari de Lingüística Aplicada de la Universitat Pompeu-Fabra. 
Hutchinson, T. y Waters, A. 1987. English for Specific Purposes: A Learning-centred Approach, Cambridge: Cambridge University Press.

Instituto Cervantes: Diccionario de términos clave de ELE, Centro Virtual Cervantes, http://cvc.cervantes.es/ensenanza/biblioteca_ele/diccio_ele/default.htm.

Johnson, D., Johnson, R. y Holubec, E. 1999. El aprendizaje cooperativo en el aula, Buenos Aires: Paidós.

Kosel, B. 2002. Problem-Based Learning in Teaching across the Curriculum. IATEFL ESP SIG NewsLetter, 21, 13-18.

Martín Peris, E. 2007. Textos y discursos en la enseñanza de EFE. Encuentro sobre el Español con Fines Específicos EFE, Fundación Campus Comillas y Universidad de Alcalá, Comillas, 8-9 feb 2007 http://www.upf.edu/pdi/dtf/ernesto.martin/archivos/ELE/EFEComillasfebrero2007.ppt

Martínez, A. y Musitu, G. (coord.). 1995. El estudio de casos para profesionales de la acción social, Madrid: Narcea.

Moirand, S. 1994. Décrire les discours de spécialité. S. Barrueco, L. Sierra y E. Hernández (coord.), Lenguas para Fines Específicos III), Alcalá de Henares: Universidad de Alcalá, 79-91.

Monge Cosín, J. 2007. La enseñanza/aprendizaje del Español como Lengua Extranjera para fines académicos: Área de Letras. Tesis de máster, Universidad de Alcalá.

Morales, P. 2008. Aprender a trabajar en equipo evaluando el proceso. L. Prieto coord.), La enseñanza universitaria centrada en el aprendizaje, Barcelona: Octaedro, 133-151.

Morales, P. y Landa, V. 2004. Aprendizaje basado en problemas. Theoria, 13, 145-157, http://redalyc.uaemex.mx/redalyc/pdf/299/29901314.pdf.

Pastor Cesteros, S. 2006. La enseñanza del español como lengua vehicular en contextos académicos. MarcoELE, 2, www.marcoele.com/num/2/index.html.

Pérez Hernández, M. C. 2002. Explotación de los córpora textuales informatizados para la creación de bases de datos terminológicas basadas en el conocimiento. Volumen monográfico de Estudios de Lingüística del Español ELiEs, 18, http://elies.rediris.es/elies18/index.html. 
Picht, H. y Draskau, J. 1985. Terminology: an introduction, Guilford: The University of Surrey.

Pierce Mcmahon, J. 2011. La aplicación de la teoría del constructivismo al aprendizaje de lenguas para fines específicos a través de la Webquest. Innovación Educativa, 11, 279-288.

Prieto, L. 2006. Aprendizaje activo en el aula universitaria: el caso del aprendizaje basado en problemas. Miscelánea Comillas. Revista de Ciencias Humanas y Sociales, 64, 124, 173-196.

Prieto, L. (coord.) 2008. La enseñanza universitaria centrada en el aprendizaje, Barcelona: Octaedro.

Quemada, B. 1978. Technique et langage. En B. Gille, Histoire des techniques, París: Gallimard.

Rey, A. 1976. Néologie en marche série b: langues de spécialité 2, Quebec: Gouvernement du Québec.

Rodríguez-Piñero Alcalá, A. I. 2010. Panorama de la enseñanza del español con fines profesionales: demanda, situación, dificultades y técnicas didácticas más empleadas. IV Encuentro sobre el Español como Lengua de Especialidad, organizado por la Fundación Comillas, Comillas Cantabria), 9 y 10 de septiembre de 2010.

Rondeau, G. 1983. Introduction à la terminologie, Chicoutimi: Gaëtan Morin.

Rosenberg, M: 2004. Never the twain shall meet. English Teaching Professional, 11/35, 36-37.

Sager, J. C., Dungworth, D. y Mcdonald, P. F. 1980. English Special Language: Principles and Practice in Science and Technology, Wiesbaden: Oscar Brandstetter.

Sanz Álava, I. 2001. Las presentaciones orales en el español profesional. Español para Fines Específicos. Actas del I Congreso Internacional de Español para Fines Específicos. Amsterdam, noviembre de 2000, Madrid: Ministerio de Educación, Cultura y Deporte, 133-141, http://cvc.cervantes.es/ensenanza/biblioteca_ele/ciefe/pdf/01/cvc_ciefe_01_0018.pdf.

Varantola, K. 1986. Popularization strategies and text functional shifts in scientific and technical writing. LSP Newsletter, 10, 2, 33-52. 
Vázquez, G. E. 2004. La enseñanza de español con fines académicos. J. Sánchez Lobato e I. Santos Gargallo dirs.), Vademécum para la formación de profesores, Madrid: SGEL, 1129-1147.

Vázquez, G. E. 2006. Un análisis didáctico del discurso académico español como contribución a la movilidad estudiantil europea. Español para Fines Específicos. Actas del III Congreso Internacional de Español para Fines Específicos. Utrecht, noviembre de 2006, Madrid: Ministerio de Educación y Ciencia, 132-144, http://cvc.cervantes.es/ensenanza/biblioteca_ele/ciefe/pdf/03/cvc_ciefe_03_0013.pdf

Velázquez-Bellot, A. 2004. Metodología teórica del proceso de elaboración de un Diseño Curricular para la enseñanza de las lenguas con fines específicos. RedELE. Revista Electrónica de Didáctica / Español como Lengua Extranjera, 2, www.mec.es/redele/index.shtml.

Villalba, F. y Hernández, M ${ }^{a}$ T. 2004. Español como segunda lengua en contextos escolares. J. Sánchez Lobato e I. Santos Gargallo, dirs.), Vademécum para la formación de profesores, Madrid: SGEL, 1225-1258.

Widdowson, H. G. 1983. Learning purpose and language use, Oxford: Oxford University Press.

Recibido: 11 mayo 2011

Aceptado: 26 octubre 2012

Revisado: 15 noviembre 2012

Publicado: 2 marzo 2013

Actualizado: 15 abril 2013 